\title{
High-Throughput and Systematic Study of Phase Transformations and Metastability Using Dual-Anneal Diffusion Multiples
}

\author{
JI-CHENG ZHAO
}

This article highlights the capabilities of dual-anneal diffusion multiples (DADMs) in performing high-throughput and systematic studies of phase transformations and metastability. DADMs create wide ranges of solid solution compositions through elemental interdiffusion during a first anneal at a high temperature. After quenching to ambient temperature, each diffusion multiple can be cut into several slices, and each slice is further annealed individually at a lower/second temperature. Phase transformations take place in the supersaturated regions of the solid solution compositions that are formed during the first anneal, leading to various precipitates due to different driving force, interfacial energy, and other factors as composition varies across the regions in the sample. By subjecting the sliced diffusion multiples individually to different anneal durations and different second anneal temperatures, very large datasets can be collected on phase transformation kinetics and evolution of precipitate morphology as a function of composition, time, and temperature. Metastable phases and their transitions to more stable phases have been systematically observed in the Fe-Cr-Mo ternary system across a wide range of composition, temperature, and anneal time, thus providing a large amount of information on metastability of the phases. The solvi of the metastable and stable phases can be systematically collected for more reliable CALPHAD assessments of the Gibbs free energy of the metastable phases. By adjusting the interfacial energy value in simulations using models such as the Kampmann-Wagner Numerical (KWN) model and matching the simulated precipitate sizes at different compositions with experimentally measured sizes of the corresponding compositions in a DADM, the interfacial energy value can be obtained. Opportunities and challenges in using DADMs to collect large datasets on precipitation kinetics and morphology will be explained to enable full utilization of the capabilities of DADMs in the future. This review not only presents experimental results collected to date, but also explains the vast more datasets that can be collected from DADMs in the future. An approach that iteratively and holistically integrates experimental results with model predictions is advocated as a very effective means to advance the understanding of various phase transformation mechanisms. In this way, the new mechanistic understanding can be integrated to more robust models to simulate the "abnormal" behaviors that are observed in DADMs, especially related to sequential precipitations of phases that are common in engineering alloys. Examples are also shown to illustrate the systematic nature of DADMs as a result of their continuously varying composition regions in catching unusual phenomena and emergent trends that are easily missed during studies using discrete compositions afforded by individual alloys.

https://doi.org/10.1007/s11661-020-05915-w

(c) The Minerals, Metals \& Materials Society and ASM International 2020

JI-CHENG ZHAO is with Department of Materials Science and Engineering, University of Maryland, College Park, MD 20742.

Contact e-mail: jczhao@umd.edu

Manuscript submitted April 12, 2020.

Article published online July 28, 2020

\section{INTRODUCTION}

A diffusion multiple assembles several pieces of pure metals and/or alloys into a highly efficient sample containing several diffusion couples and triples, ${ }^{[1]}$ as shown in Figure 1(a) for a Co-Cr-Fe-Mo-Ni diffusion multiple that contains 10 binary diffusion couples and 8 diffusion triples. ${ }^{[2,3]}$ Local equilibrium analysis of 
diffusion profiles obtained using electron probe micro-analysis (EMPA) across the interfaces between the phases provides equilibrium tie-line compositions and a large number of tie-lines together provide the isothermal section phase diagrams, as shown in Figures 1(c) and (d) for the Fe-Cr-Ni and Fe-Cr-Mo ternary systems. ${ }^{[2,3]}$ A recent example of systematic determination of phase diagrams is the Co-Al-X ( $\mathrm{X}=$ $\mathrm{W}, \mathrm{Mo}, \mathrm{Nb}, \mathrm{Ni}, \mathrm{Ta})$ and Co-Ni-X $(\mathrm{X}=\mathrm{W}, \mathrm{Mo}, \mathrm{Nb}$, Ta) systems for the development of Co-based superalloys. ${ }^{[4,5]}$ Diffusion composition profiles collected from diffusion couples inside diffusion multiples allow both interdiffusion and impurity diffusion coefficients to be reliably extracted using a forward-simulation analysis. ${ }^{[6-8]}$ For instance, measurement of diffusion coefficients in $\mathrm{Ti}-(\mathrm{Cr}, \mathrm{Hf}, \mathrm{Mo}, \mathrm{Nb}, \mathrm{Ta}, \mathrm{V}, \mathrm{Zr})$ binary systems has provided the most comprehensive measurement to date for the bcc phase of Ti-based systems..$^{[9,10]}$

In addition to phase diagrams and diffusion coefficients, the composition gradients (for binary systems) and composition regions (for ternary and higher order systems) formed in diffusion multiples have been employed to efficiently collect various physical and thermophysical properties as a function of composition. ${ }^{[1]}$ Such measurements are enabled by the development and application of micron-resolution localized property measurement tools for thermal conductivity, ${ }^{[12,13]}$ specific heat, ${ }^{[14]}$ coefficient of thermal expansion, ${ }^{[15]}$ and elastic constants, ${ }^{[16,17]}$ in addition to hardness and modulus that are readily accessible using nanoindentation. ${ }^{[18,19]}$

All the above results are obtained from diffusion multiples that are annealed at a single temperature and then quenched to retain the composition-varying single-phase compositions to ambient temperature for measurements. In this regard, it is highly desirable to avoid any phase transformation during quench such that phase-based properties can be obtained for all or most of the single-phase compositions that are formed in the diffusion multiples.

A question being asked often is whether diffusion multiples can be employed to effectively study phase precipitation and morphological evolution of two-phase or multi-phase materials. After all, precipitates and microstructure heterogeneities contribute to most of the strength of widely used engineering alloys. It is thus highly desirable to leverage diffusion multiples for efficient studies of phase precipitation to help validate and improve precipitation models and design new precipitation-strengthened alloys. This article highlights the recent progress in moving towards this direction.

The experimental approach described thereafter follows a series of prior investigations that leverage the composition gradients formed in diffusion couples to perform high-throughput studies of phase transformations. ${ }^{[20-31]}$ Most notably, two decades ago, Borgenstam and Hillert started to employ composition gradients in diffusion couples to study massive transformations in an effective and systematic manner. ${ }^{[20]}$ The current study extends such high-throughput studies from composition gradients in diffusion couples (i.e., composition variation along one direction) to composition ranges in diffusion multiples (i.e., composition variations along two directions) to enable even more efficient and systematic studies of phase transformations and microstructural evolution, especially for ternary and higher order systems.

It is noted that all such studies rely on the formation of relatively shallow composition gradients in diffusion couples and diffusion multiples such that the width and spread of the diffusion zone are at least an order of magnitude larger than the microstructural features being examined except for massive transformations and martensitic transformations where long-range diffusion does not play an appreciable role. In this connection, the diffusion anneal needs to be designed carefully to enable large diffusion distances to minimize the effect of composition gradients themselves on the phase transformations to be studied.

\section{DUAL-ANNEAL DIFFUSION MULTIPLES: THE IDEA}

Cao and Zhao developed dual-anneal diffusion multiples (DADMs) with the original objective of determining intermediate temperature phase diagrams. ${ }^{[2,3]}$ There is a significant worldwide shortage of experimental phase diagram data at intermediate temperatures where most alloys are used in service. This shortage results in large uncertainty of the assessed thermodynamic data and thus relatively poor ability to accurately predict phase stability and driving force for phase transformations during materials processing and usage at the intermediate temperature range. The DADM approach was developed and demonstrated for efficient determination of intermediate temperature phase diagrams by creating wide ranges of compositions of solid solutions and intermetallic compounds during a first anneal at $1200{ }^{\circ} \mathrm{C}$, as shown in the highlighted single-phase regions in Figures 1(c) and (d) for the $\mathrm{Fe}-\mathrm{Cr}-\mathrm{Ni}$ and $\mathrm{Fe}-\mathrm{Cr}-\mathrm{Mo}$ systems. ${ }^{[2,3]}$ A subsequent second anneal at an intermediate temperature (e.g., $900{ }^{\circ} \mathrm{C}$ ) induced various precipitates from the supersaturated solid solution phases. Local equilibrium analysis of EPMA composition profiles across the interfaces between large precipitates and the matrix phases provides equilibrium tie-lines for the establishment of the intermediate temperature phase diagrams, as shown in Figures 1(e) and (f) for the $900{ }^{\circ} \mathrm{C}$ isothermal sections of the $\mathrm{Fe}-\mathrm{Cr}-\mathrm{Ni}$ and $\mathrm{Fe}-\mathrm{Cr}-\mathrm{Mo}$ systems. ${ }^{[2,3]}$

The Co-Cr-Fe-Mo-Ni diffusion multiple set (Figure 1) contains 8 ternary systems and the high-temperature annealed diffusion multiples are sliced into several pieces and annealed at 4 intermediate temperatures. Such multiplication effect $(8 \times 4)$ greatly accelerates phase diagram determination in comparison with the traditional individual alloy approach which would require dozens of individual alloys to be made for each ternary system. The time-saving is not only on the avoidance of making hundreds of individual alloys (each equilibrated alloy can provide one tie-line or a set of tie-triangle data), but also on the significant time reduction in characterizing the annealed alloy samples 


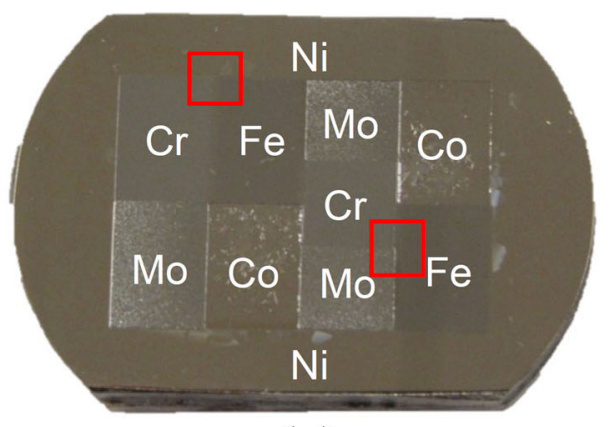

(a)

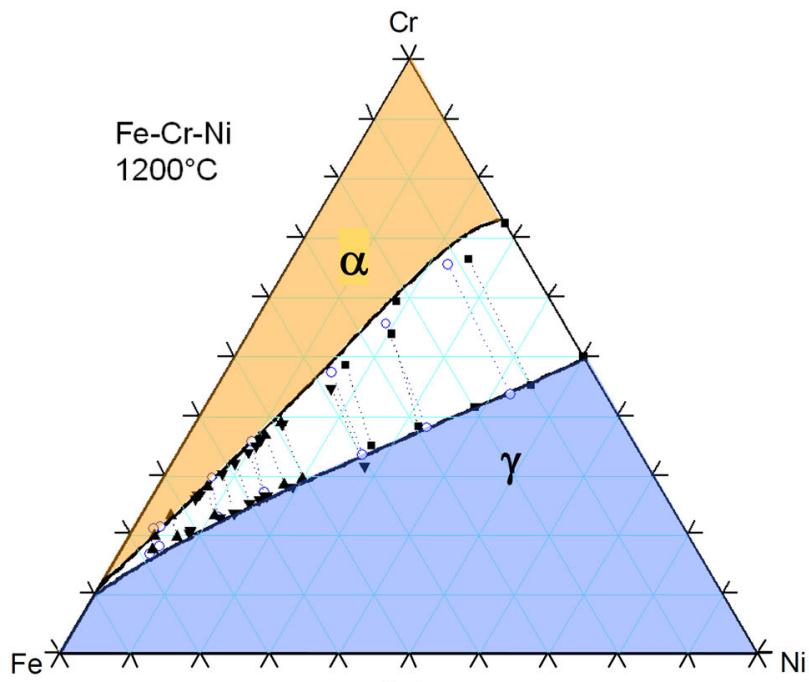

(c)

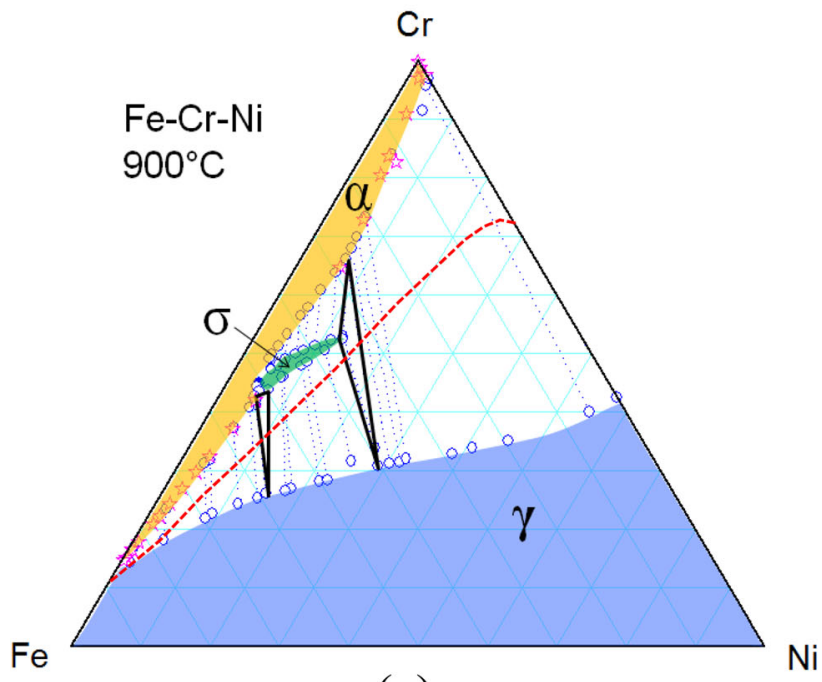

(e)

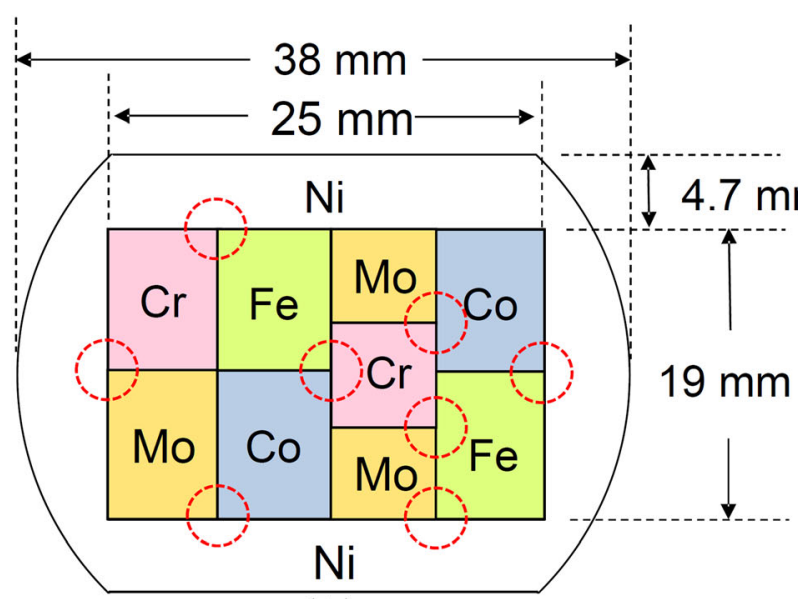

(b)

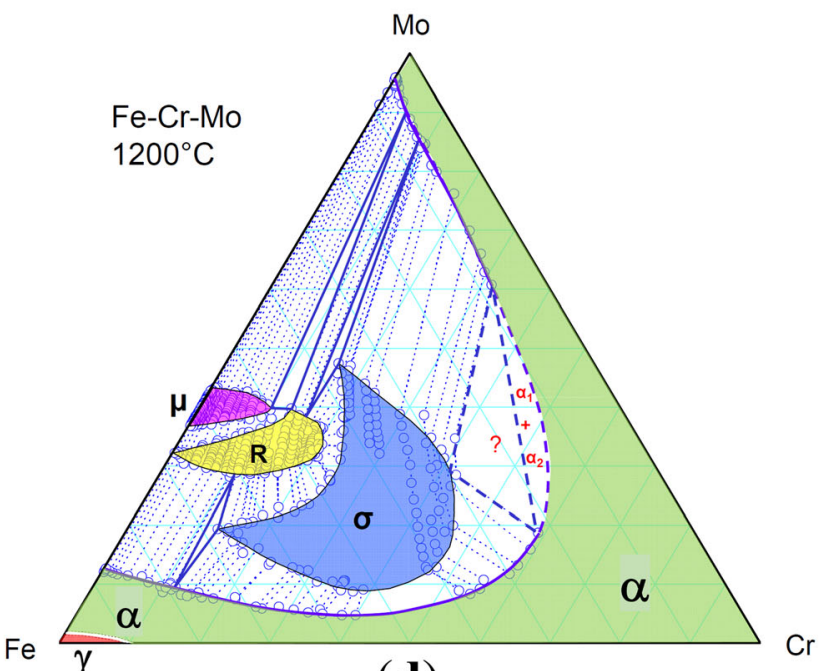

(d)

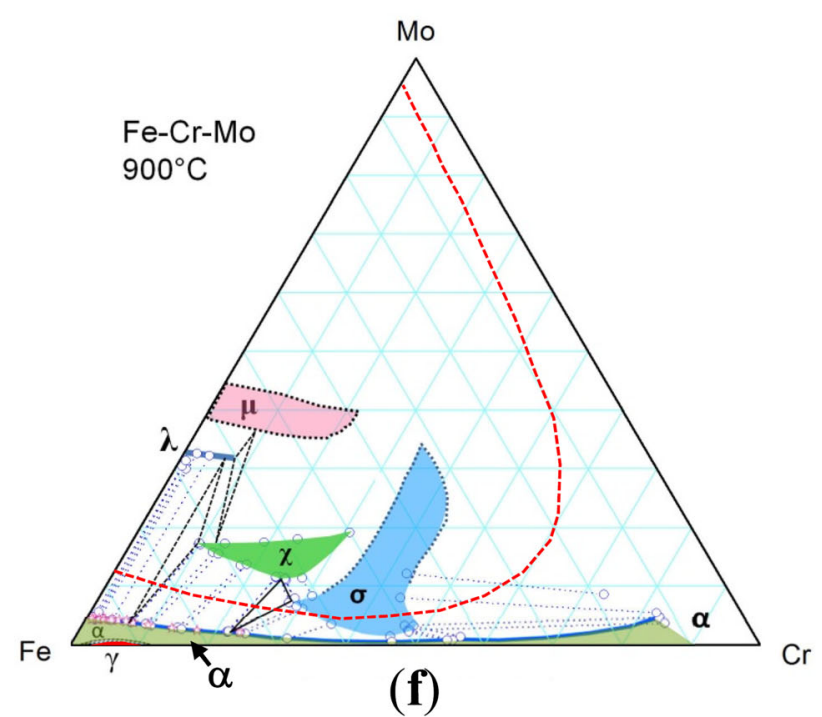

Fig. 1-Co-Cr-Fe-Mo-Ni diffusion multiple and phase diagrams measured from the sample set: $(a)$ optical photo; $(b)$ schematic of the dimensions; $(c) \&(d) 1200{ }^{\circ} \mathrm{C} \mathrm{Fe}-\mathrm{Cr}-\mathrm{Ni}$ and $\mathrm{Fe}-\mathrm{Cr}$-Mo isothermal sections determined from the single anneal $\left(1200^{\circ} \mathrm{C}\right)$ diffusion multiple; and (e) and $(f) 900{ }^{\circ} \mathrm{C}$ isothermal sections of the Fe-Cr-Ni and Fe-Cr-Mo ternary systems obtained from a DADM that was first annealed at 1200 ${ }^{\circ} \mathrm{C}$ for $500 \mathrm{~h}$ and then at $900{ }^{\circ} \mathrm{C}$ for $500 \mathrm{~h} \cdot{ }^{[2,3]}$ Part of the $900{ }^{\circ} \mathrm{C}$ Fe-Cr-Mo isothermal section with Fe concentration less than 50 at. pct is not determined. Reprinted with permission from Refs. [2] and [3]. 
one by one using SEM and EPMA. For both SEM and EPMA, only one or a few samples can be loaded into the systems each time, waiting for vacuum and then performing analyses. One can appreciate the enormous efficiency gain provided by the DADM approach. Some results of the $\mathrm{Fe}-\mathrm{Cr}-\mathrm{Ni}$ and $\mathrm{Fe}-\mathrm{Cr}-\mathrm{Mo}$ ternary systems are summarized in Figure 1 as examples. ${ }^{[2,3]}$

It is a bit easier to use a binary system to explain the idea of employing DADMs to efficiently study phase transformation and microstructure evolution, as shown in Figure 2 for the Ni-NiAl diffusion couple inside a Ni-NiAl-Co-Cr-Cu-Fe diffusion multiple, Figure $2(\mathrm{~g}) .^{[32]}$ The diffusion multiple was annealed first at $1000{ }^{\circ} \mathrm{C}$ for 510 hours to create the composition gradient for each phase, quenched to ambient temperature to retain the high-temperature phases and compositions, and then annealed at $700{ }^{\circ} \mathrm{C}$ for 24 hours to induce phase precipitation as a function of composition/ location in the supersaturated region. The Ni-rich part of the Ni-Al phase diagram in Figure 2(a) clearly shows that the Al solubility in the Ni-based fcc phase at 1000 ${ }^{\circ} \mathrm{C}$ is $\sim 14.7$ at. pct, which is higher than that at $700{ }^{\circ} \mathrm{C}$ ( 11.2 at. pct); thus, the composition between the two vertical dashed lines in Figure 2(a), which is equivalent to the composition between the two horizontal lines in Figure 2(b), is supersaturated at $700{ }^{\circ} \mathrm{C}$. With increasing composition from 11.2 to 14.7 at. pct, the driving force for the $\gamma^{\prime}\left(\mathrm{Ni}_{3} \mathrm{Al}\right)$ phase precipitation increases, leading to different nucleation rate and coarsening kinetics. As a result, different $\gamma^{\prime}$ size and particle density were observed as a function of location/composition, as shown in Figure 2(c) with two higher magnification scanning electron microscopy (SEM) images near the two extremes of compositions showing in Figures 2(d) and (e). In this regard, DADM enables more systematic and efficient studies of phase transformations as a function of composition, in comparison with one-alloy-at-a-time practice. In other words, DADM is equivalent to studying the phase transformation for a range of compositions (or several alloys of individual compositions) simultaneously. The $1000{ }^{\circ} \mathrm{C}$-annealed (and then quenched) diffusion multiple can be cut into several slices to be subjected to different precipitation anneal durations and different precipitation temperatures to systematically study phase transformations as a function of composition, temperature and time, thus providing a large amount of data on precipitation kinetics and morphology. This approach is identical to the high-throughput study of phase transformations using diffusion couples ${ }^{[20-31]}$ as mentioned in the Introduction.

By taking advantage of the particle size distribution at different location/composition in a DADM and matching the experimental results to simulation predictions using the Kampmann and Wagner Numerical (KWN) model ${ }^{[33,34]}$ with the interfacial energy value as a simulation input parameter, it is possible to extract the interfacial energy between the precipitates and the matrix. The interfacial energy between the $\gamma^{\prime}$ precipitates and the Ni-based fcc matrix at $700{ }^{\circ} \mathrm{C}$ was evaluated to be $\sim 12 \mathrm{~mJ} / \mathrm{m}^{2}$, which is in the middle of a range of values reported for the $\mathrm{Ni}-\mathrm{Al}$ system. ${ }^{[32]}$
For ternary (and potentially higher order) systems, DADMs provide even greater amounts of systematic information when several phases, including metastable phases, are forming as a function of composition, anneal time, and temperature. Observations on two ternary systems, $\mathrm{Fe}-\mathrm{Cr}-\mathrm{Mo}$ and $\mathrm{Fe}-\mathrm{Cr}-\mathrm{Ni}$, will be described in the subsequent sections to illustrate the enormous amount of systematic data that can be efficiently obtained from DADMs to help understand the phase transformation kinetics, mechanisms, morphological evolution, and metastability across a wide range of composition. The results are obtained from the $\mathrm{Fe}-\mathrm{Cr}-\mathrm{Mo}$ and $\mathrm{Fe}-\mathrm{Cr}-\mathrm{Ni}$ tri-junctions (diffusion triples) marked with two squares in Figure 1(a).

\section{PHASE PRECIPITATION IN THE FE-CR-MO TERNARY SYSTEM}

The Fe-Cr-Mo diffusion triple created all the single-phase compositions for each phase as highlighted in Figure 1(d) with various colors since all three elements were diffusing between and among them during the first anneal at $1200{ }^{\circ} \mathrm{C}$ for 500 hours. This is equivalent to the formation of the complete single-phase Ni-based fcc phase composition at $1000{ }^{\circ} \mathrm{C}$, from 0 at. pct $\mathrm{Al}$ to 14.7 at. pct $\mathrm{Al}$, for the Ni-Al case as shown in Figures 2(b) and (f). In other words, all the bcc $(\alpha)$ phase compositions near the bottom and on the right-hand side of Figure 1(d) were present at the $1200{ }^{\circ} \mathrm{C}$-annealed diffusion multiple. Water quench after the $1200{ }^{\circ} \mathrm{C}$ anneal was able to retain all the single-phase composition to ambient temperature, showing no precipitates in the vast bec phase region in the sample. ${ }^{[3]}$

One can clearly see much lower solubility of Mo in the $\mathrm{Fe}-\mathrm{Cr}$-based bcc phase (near the bottom of the isothermal section) at $900{ }^{\circ} \mathrm{C}$ than that at $1200{ }^{\circ} \mathrm{C}$ by comparing Figure 1(f) with Figure 1(d). The dashed red line in Figure 1(f) is the $1200{ }^{\circ} \mathrm{C}$ solubility line superimposed on the $900{ }^{\circ} \mathrm{C}$ isothermal section, showing the solubility difference. The compositions between the red dashed line and the $900{ }^{\circ} \mathrm{C}$ solubility limit which is represented as the phase boundary of the $\alpha$ phase (solid line) are supersaturated at $900{ }^{\circ} \mathrm{C}$. Locations corresponding to these compositions will have precipitates after being annealed at $900{ }^{\circ} \mathrm{C}$. This is very similar to the supersaturated compositions between 14.7 at. pet to 11.2 at. pct $\mathrm{Al}$ in the $\mathrm{Ni}-\mathrm{Al}$ case when the temperature is reduced from $1000{ }^{\circ} \mathrm{C}$ to $700{ }^{\circ} \mathrm{C}$. The big difference for the Fe-Cr-Mo ternary system is that the supersaturated compositions cover different two-phase and three-phase regions in the $700{ }^{\circ} \mathrm{C}$ isothermal section of Figure 1(f) as the $\mathrm{Cr}$ concentration increases (moving from the Fe-rich corner towards $\mathrm{Cr}$ ): $\alpha+\lambda$ (C14-Laves), $\alpha+\lambda+\chi, \alpha+$ $\chi, \alpha+\chi+\sigma$, and $\alpha+\sigma$. One can thus foresee very rich precipitation information as a result of the competition between these phases $(\lambda, \chi$, and $\sigma)$ across the supersaturated compositions with different concentrations of Mo and $\mathrm{Cr}^{3]}$ Additional metastable phases can potentially form as precipitates as well, adding opportunities to systematically study metastability in this ternary system. 

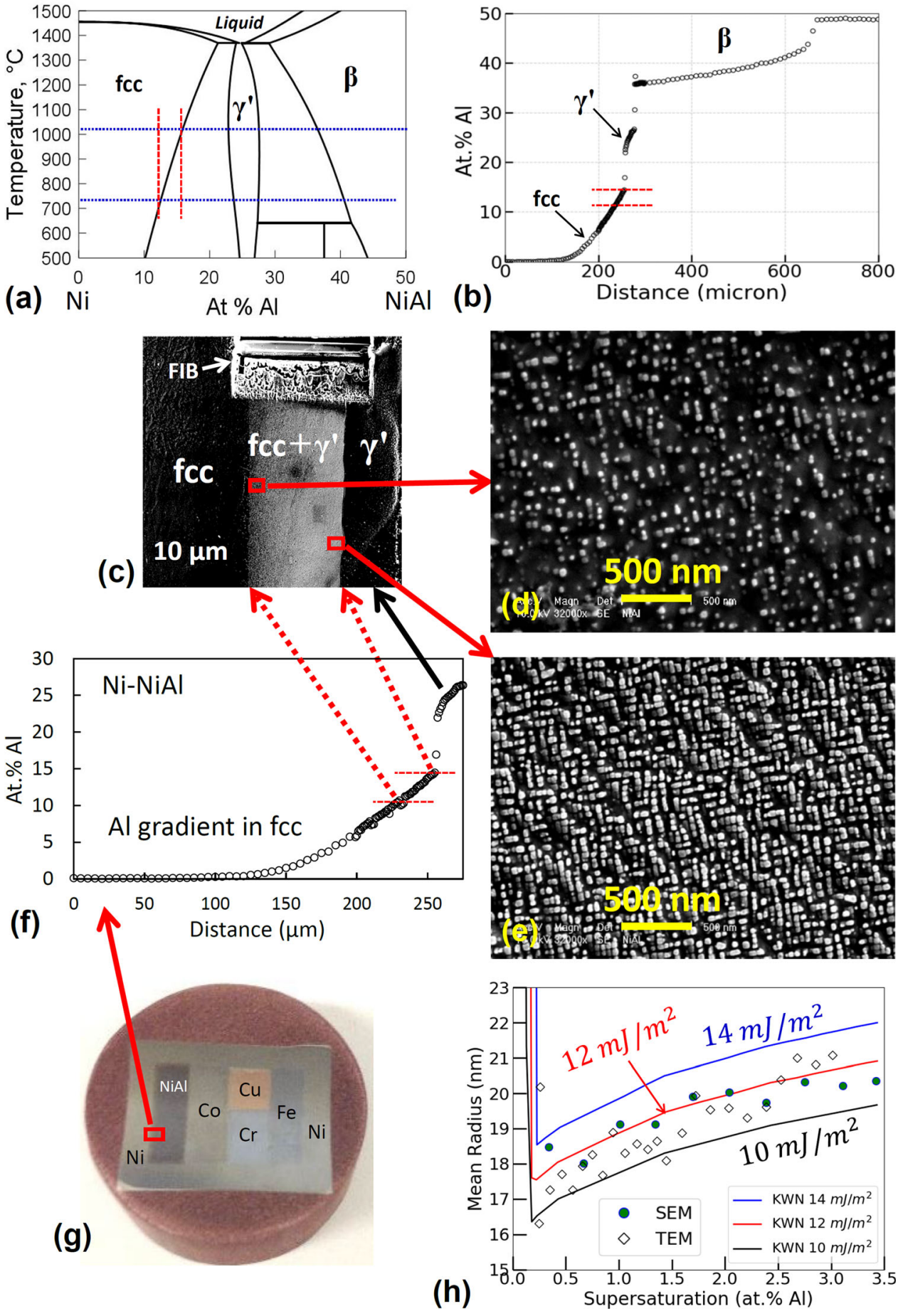

Fig. 2-Explanation of the DADM approach using the Ni-Al binary system: (a) Ni-rich part of the Ni-Al phase diagram showing the solubility difference; $(b)$ EMPA Al composition profile across the Ni-NiAl diffusion couple region after being annealed at $1000{ }^{\circ} \mathrm{C} 510 \mathrm{~h}$ showing the $\mathrm{Al}$ gradient in the fcc region; (c) SEM image showing the $\gamma^{\prime}$ precipitation from the supersaturated region after the diffusion multiple was subjected to a second/precipitation anneal at $700{ }^{\circ} \mathrm{C}$ for $24 \mathrm{~h} ;(d)$ and $(e)$ SEM images of the $\gamma^{\prime}$ precipitates at two locations/supersaturations marked in (c); $(f)$ expanded view of the $\mathrm{Al}$ concentration gradient in the fcc region with the supersaturated compositions/locations marked in relation to the locations in (c); $(g)$ Optical photo of the Ni-NiAl-Co-Cr-Cu-Fe DADM showing the Ni-NiAl diffusion couple location; and $(h)$ comparison between the simulated (lines) and experimentally measured (symbols) $\gamma^{\prime}$ mean precipitate radius as a function of Al supersaturation showing a match to an interfacial energy value of $12 \mathrm{~mJ} / \mathrm{m}^{2}$. The red dashed lines in (a), (b) and (f) indicate the supersaturated area/composition during the second anneal $\left(700{ }^{\circ} \mathrm{C}\right)$, which corresponds to the fcc $+\gamma^{\prime}$ area in the SEM image in (c). Adapted from Ref. [32] with permission.

There is even a small composition region where the $\sigma$ phase single-phase region dips below the $1200{ }^{\circ} \mathrm{C} \alpha$ phase single-phase region, referring to the small region of the $\sigma$ phase below the dashed read line in Figure 1(f), where direct $\alpha$ to $\sigma$ massive transformation without composition change is possible. It is noted that the 
Fe-lean part of the $700{ }^{\circ} \mathrm{C}$ isothermal section of the $\mathrm{Fe}-\mathrm{Cr}-\mathrm{Mo}$ system, Figure 1(f), with Fe concentration less than 50 at. pct has not been determined, but does not interfere with the subsequent description since the results are all focused on the Fe-rich part of the phase diagram which is well determined.

The diffusion multiple that was quenched after the first anneal at $1200{ }^{\circ} \mathrm{C}$ for 500 hours was cut into $\sim 5 \mathrm{~mm}$ thick slices and then subjected to a second anneal at 900 ${ }^{\circ} \mathrm{C}$ for 5, 50, and 500 hours (one slice each). Figure 3 shows the microstructures of the Fe-Cr-Mo tri-junction of these Co-Cr-Fe-Mo-Ni DADMs. The morphological changes are the results of different crystal structures of the precipitate phases, different nucleation and growth kinetics, different local compositions (thus different driving forces and nucleation rates), and differences in other factors such as interfacial energy, elastic strain energy, and the competitions/transitions between the metastable and stable phases formed during various stages of the precipitation process. The composition-dependent and time-dependent morphological information provides very valuable insights into the phase transformation kinetics and the competition between the stable and metastable phases as described subsequently.

\section{DISCOVERY OF "ABNORMAL" GROWTH OF PRECIPITATES AND POTENTIAL NEW MECHANISMS}

The wide continuously varying compositions of the bcc $(\alpha)$ phase of the Fe-Cr-Mo ternary system created by the first anneal of the Co-Cr-Fe-Mo-Ni diffusion multiple at $1200{ }^{\circ} \mathrm{C}$ for 500 hours provide an opportunity to systematically study phase precipitation as a function of composition (location in the DADMs), precipitation temperature (slices of the diffusion multiple set have been dual-annealed at $900{ }^{\circ} \mathrm{C}, 800{ }^{\circ} \mathrm{C}, 700{ }^{\circ} \mathrm{C}$, and 600 ${ }^{\circ} \mathrm{C}$ ), and precipitation anneal time (from 5 to 50 to 500 hours). For instance, as the precipitation anneal time increases from 5 to 50 to 500 hours, the $\chi$ phase precipitation region expands towards the left in Figure 3, consuming the metastable R-phase along the way. (The red vertical dashed line on the right shows a common horizontal location for all the three samples and the red vertical dashed line to the left is the left-most front of the $\chi$ phase precipitation in the 5-hour annealed sample). This can be appreciated by examining the precipitates inside the small square box in the middle of Figure 3. The fine R-phase precipitates in the small square box in Figure 3(a) are consumed by the equilibrium $\chi$ phase at the same box location (thus presumably the same composition) in Figure 3(b) of the 50-hour anneal sample; and the $\chi$ phase has expanded beyond (to the left) of the same box location in the 500-hour anneal sample in Figure 3(c). The sizes of the $\chi$ phase at this expansion front are much larger than normal $\chi$ phase precipitates formed in the circled regions in Figure 3 where the normal nucleation, growth and coarsening take place for the $\chi$ phase without the interference of the metastable R-phase.
Figure 4 compares the average radius of the $\chi$ phase at the expansion front with that at the circled regions inside the $\chi$ phase precipitation region in Figure 3, showing drastically "abnormal" sizes at the expansion fronts. This phenomenon has not been reported in the literature before. The continuous (and shallow) composition variations created in DADMs together with time-series images allow direct observation of this new phenomenon. It is important to understand this phenomenon since many alloys such as Al alloys go through several metastable phases before the formation of the equilibrium precipitates. If similar "abnormal" growth/size emerges as a result of the growth of one phase at the expense of a less stable phase under certain conditions, it would be important to understand and model this behavior to avoid erroneous conclusions. This point can be appreciated by performing a hypothetical study with two alloys: the first one with a nominal composition represented by the average composition of the circled regions in Figure 3 and the second alloy with a nominal composition of the small square boxes in Figure 3. After precipitation anneal at $900{ }^{\circ} \mathrm{C}$ for 5 hours, 50 hours and 500 hours, the first alloy would have fine $\chi$ phase precipitates as represented at the bottom curve of Figure 4 and can be modeled with the classical KWN models. ${ }^{[33,34]}$ The result of the second alloy would be completely different. After 5-hour anneal at $900{ }^{\circ} \mathrm{C}$, very fine precipitates of a metastable $\mathrm{R}$-phase would be observed as those inside the small square box in Figure 3(a); after 50-hour anneal, large $\chi$ phase precipitates as those inside the small square box in Figure 3(b) would be observed; and after 500 -hour anneal at $900{ }^{\circ} \mathrm{C}$, very large $\chi$ precipitates as those inside the small square box in Figure 3(c) would be observed. If someone would employ the coarsening kinetics of the second alloy to obtain the interfacial energy or other kinetic parameters for the $\chi$ phase, very erroneous conclusions would be drawn. Similar behavior of "abnormal" sizes was also observed for other phases in the DADMs, e.g., the location of the large square on the left of Figure 3(b) when the metastable phase grew at the expense of the R-phase and the location of a large solid arrow in Figure 3(c) where the $\sigma$ phase grew at the expense of the $\chi$ phase. Thus, this phenomenon may be commonplace, but not previously reported because individual alloy studies would not provide a direct comparison as nicely showing in Figure 3.

Both experimental characterization and modeling may be employed to study the mechanism(s) of this new phenomenon. A few hypotheses for the "abnormal" sizes at the $\chi$ phase expansion fronts can be modeled to test various potential mechanisms. The first hypothesis is that at the very left expansion front of the $\chi$ phase (near the small square box in Figure 3(c)) in the 900 ${ }^{\circ} \mathrm{C}$-500-hour anneal sample, the driving force for $\chi$ phase precipitation is close to zero, similar to all the other compositions at the circumference of the $\chi$ phase precipitation region in Figure 3(c). With near zero driving force for the $\chi$ phase precipitation, the nucleation rate is extremely low; the nuclei are few and far apart, and they can grow with sufficient supplies of solutes (especially Mo in the case of the $\chi$ phase 


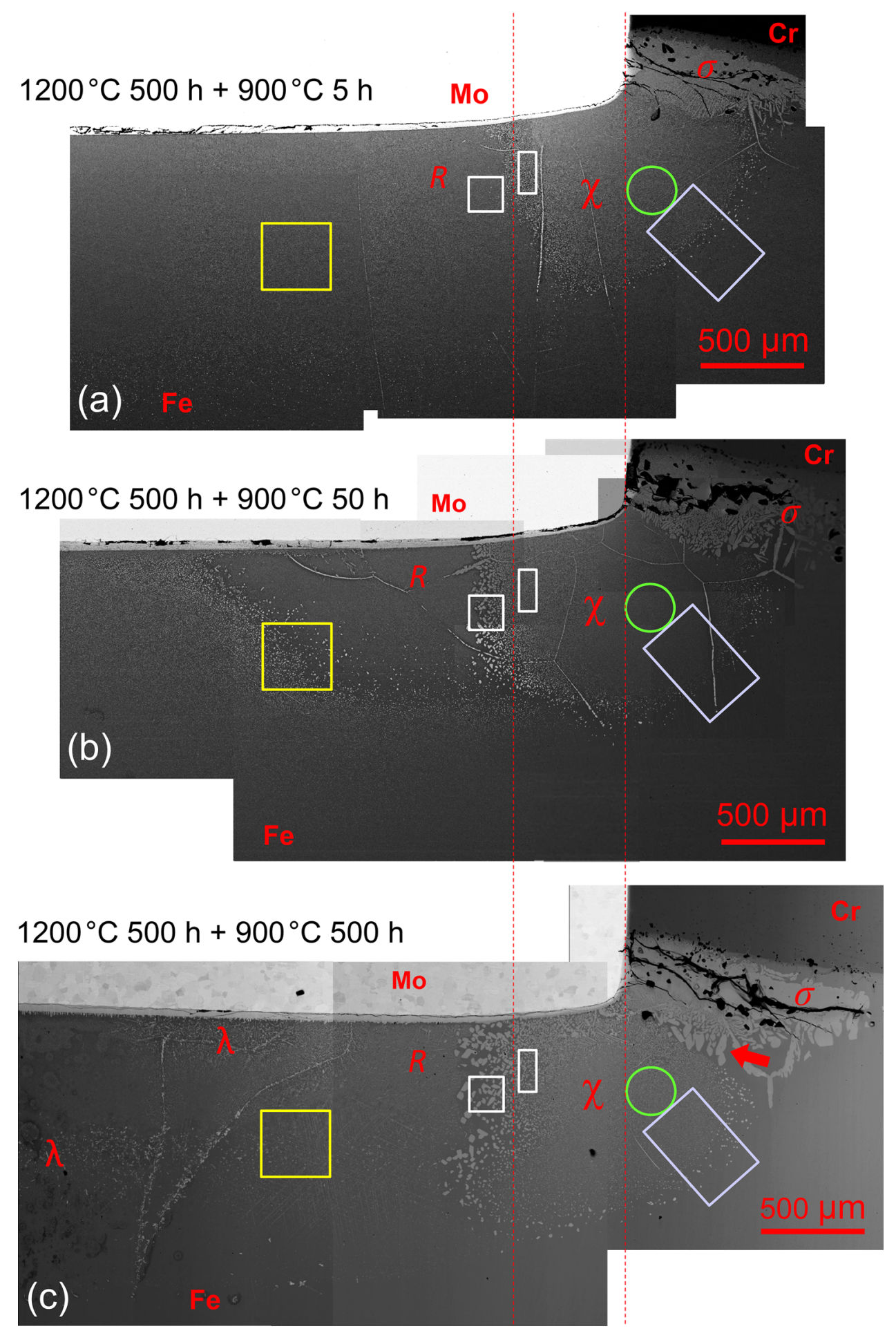

Fig. 3- SEM image montages showing the phase precipitation in the Fe-Cr-Mo tri-junction area of DADMs that were annealed at $1200{ }^{\circ} \mathrm{C}$ for $500 \mathrm{~h}$ to form wide ranges of solid solution composition and then annealed at $900{ }^{\circ} \mathrm{C}$ for different time durations to reveal the precipitation morphology and distribution as a function of anneal time at $900{ }^{\circ} \mathrm{C}$ from $5 \mathrm{~h}(a)$ to $50 \mathrm{~h}(b)$ to $500 \mathrm{~h}(c)$. (c) is reprinted with permission from Ref. [3].

precipitation where $\mathrm{Cr}$ concentrations in the $\chi$ and $\alpha$ phases are quite similar) without the need to sharing the solutes with nearby particles. A preliminary simulation was performed using DICTRA ${ }^{[35]}$ to test whether un-impinged growth of the $\chi$ phase can reach the "abnormal" size. DICTRA takes Gibbs energy functions of the phases from Thermo-Calc ${ }^{[36,37]}$ (using the TCFE9 database) and diffusion coefficients from its own mobility database (MOBFE4) to enable simulations of diffusional growth under the local/interfacial 


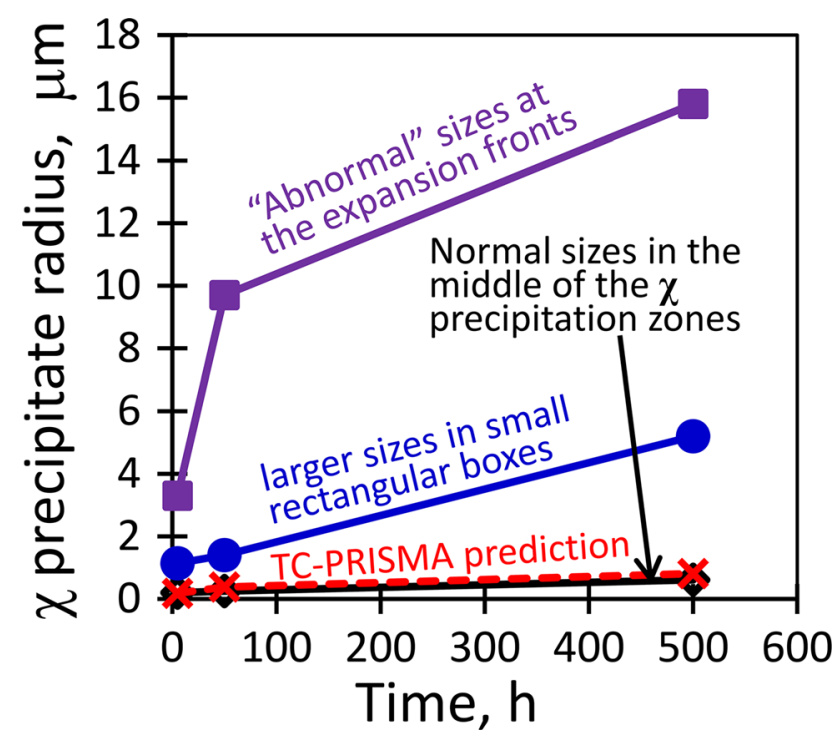

Fig. 4-Abnormal particle radius of the $\chi$ phase at its left expansion fronts (near the small square boxes) in Fig. 3 in comparison with that inside the small rectangular boxes and circled regions in Fig. 3..

equilibrium assumption. The results show that a single nucleus of the $\chi$ phase in an infinitely large $\alpha$ matrix can grow to a spherical particle with a radius of $\sim 65 \mu \mathrm{m}$ in an alloy of Fe-9Cr-9Mo (at. pct) (which is close to the composition of the small square box in Figure 3(c)) after being annealed at $900{ }^{\circ} \mathrm{C}$ for 500 hours, indicating that pure diffusional growth can lead to very large $\chi$ precipitates at $900{ }^{\circ} \mathrm{C}$ after 500 hours if the growing particle has sufficient solutes to be drawn un-impinged. Even though the $\chi$ phase particles at the left expansion front near the small square box in Figure 3(c) are large but they have neighbors who are competing for the solutes in the matrix phase. Thus, their radii are not up to $\sim 65 \mu \mathrm{m}$. To simulate the various particle sizes and distributions as well as coarsening rates, models need to couple all the nucleation, growth and coarsening events, thus requiring the KWN type of models. ${ }^{[33,34]}$

The KWN models ${ }^{[33,34]}$ treat classical nucleation, growth, and coarsening as overlapping processes numerically by discretizing the precipitate particle size distributions into segments (classes) and then tracking their evolution with time. The thermodynamic driving force and interfacial energy are two major input parameters needed for the classical nucleation theory to yield the critical nucleus sizes and number density. Various growth and/or dissolution models (such as Zener's model ${ }^{[38]}$ ) are implemented with inclusion of the Gibbs-Thomson effect; and they have the advantage of describing the growth or shrink rate of particles during coarsening such that the Liftshitz-Slyozov-Wagner (LSW) coarsening equation ${ }^{[39,40]}$ becomes unnecessary. Diffusion coefficients are also essential input parameters for modeling the nucleation, growth and coarsening processes. The KWN models are described in detailed reviews. ${ }^{[33,34,41]}$ The TC-PRISMA code ${ }^{[42,43]}$ implemented the KWN models to handle precipitations in multicomponent systems using an elegant scheme developed by Chen et al. ${ }^{[42]}$

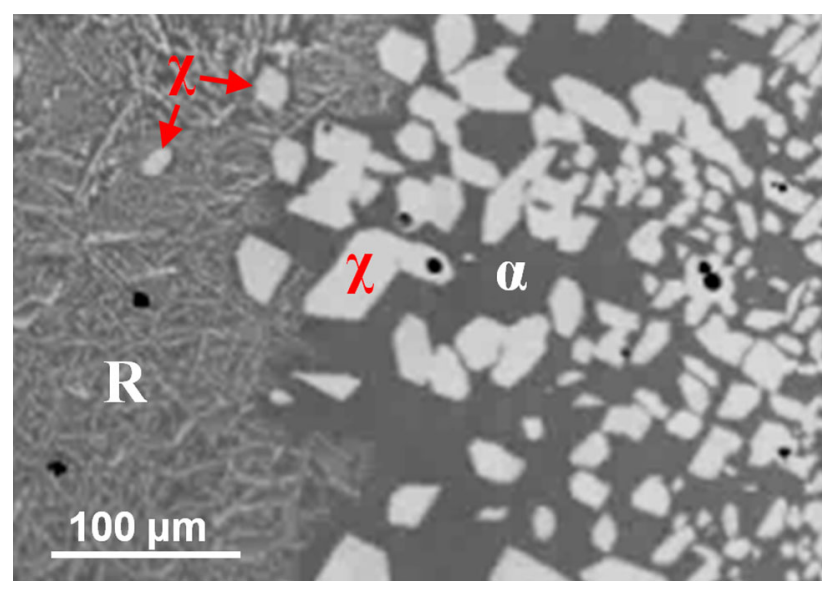

Fig. 5-SEM image from an area near the small square box in Fig. 3(c) showing $\chi$ phase formation from the metastable R-phase.

The second hypothesis is that $\chi$ nucleates at the interface between the R-phase and the $\alpha$ matrix and grows by consuming the R-phase to provide the solutes for the $\chi$ phase. The two arrows in Figure 5 point to two $\chi$ phase particles that grew from the $\mathrm{R}$ precipitates and the $\alpha$ matrix, providing some support for this hypothesis. Detailed TEM characterization using focused ion beam (FIB) extraction of TEM foils will likely be able to find smaller $\chi$ phase particles just nucleated from the $\mathrm{R}$-phase (and the $\alpha$ matrix) near this area and provides insights into the nucleation mechanism (Some of the brighter thin precipitates among the fine R-phase on the left-hand-side of Figure 5 may be the $\chi$ phase). The $\mathrm{R}$-phase is a metastable phase at $900{ }^{\circ} \mathrm{C}$, but it is a stable phase at $1200{ }^{\circ} \mathrm{C}$. If its Mo concentration at 900 ${ }^{\circ} \mathrm{C}$ is assumed to be the same as that at $1200{ }^{\circ} \mathrm{C}$ (the compositions of some of the intermetallic compounds are not strongly composition-dependent), then a value of around 30 at. pct Mo can be assumed for $900{ }^{\circ} \mathrm{C}$ according to the $1200{ }^{\circ} \mathrm{C}$ isothermal section, Figure 1(d). The Mo concentration of the $\alpha$ phase matrix at $900{ }^{\circ} \mathrm{C}$ is around $\sim 3$ at. pct. ${ }^{[3]}$ Thus, the interface between the R-phase and the $\alpha$ phase can easily provide the right amount of Mo concentration for the nucleation and growth of the $\chi$ phase whose composition varies from $\sim 12$ at. pet to $\sim 18$ at. pct Mo. If this hypothesis is correct, why aren't there a large number of the $\chi$ phase nuclei formed at the enormous numbers of the interfaces between the fine R-phase and the $\alpha$ matrix? The answer may again point to the near zero driving force for the $\chi$ precipitation at the expense of the $\mathrm{R}$ and $\alpha$ phases. Preliminary Thermo-Calc calculations show that the driving force for nucleation of the $\chi$ phase directly from a supersaturated $\alpha$ solid solution of Fe-9Cr-9Mo (at. pct) is as high as $-898 \mathrm{~J} /$ (mole of atoms); whereas the driving force for nucleation of the $\chi$ phase from the mixture of the $R$ and $\alpha$ phases is only - $209 \mathrm{~J} /$ (mole of atoms). Even though there are a large number of potential nucleation sites, the near zero driving force makes the nucleation rate very low. 
The third hypothesis is that the composition gradients created by the $1200{ }^{\circ} \mathrm{C}-500$-hour anneal, even though very shallow, may play a role at the nucleation, growth, and coarsening of the precipitates, especially at the $\chi$ precipitation front, ahead of which there are shallow composition gradients for both $\mathrm{Cr}$ (left to right) and $\mathrm{Mo}$ (top to bottom). It may be easier to explain this hypothesis using the tilted rectangular boxes in Figure 3 where one can see that the precipitation front moved towards the lower left (towards the equilibrium solvus compositions) and the $\chi$ precipitate sizes increase with increasing anneal time at $900{ }^{\circ} \mathrm{C}$. Such a progression is exactly the same as what was observed by Miyazaki for the Ni-Al binary case. ${ }^{[27]}$ The larger $\chi$ precipitates at the front in the tilted rectangular box in Figure 3(b) have the privilege of extracting solutes from the single-phase matrix phase ahead of them, whereas those behind the front have to share the solutes with the surrounding precipitates. The "front effect" on the left expansion front of the $\chi$ phase in Figure 3 is similar except that the $\chi$ phase is nucleating and growing from the two-phase mixture of the $\mathrm{R}$ and $\alpha$ phases with a more pronounced $\chi$ precipitate size gradient.

There is evidence against such a "front effect". For instance, the $\gamma^{\prime}$ precipitate size and distribution can be reproduced in a range of compositions in the dual-anneal Ni-NiAl diffusion couple (with a composition gradient) by performing KWN simulations assuming individual compositions without considering the "front effect", as shown in Figure 3(h). In addition, Miyazaki performed phase-field simulations to show that the composition gradient in his "macro-gradient" samples has little effect on the precipitation kinetics. ${ }^{[27]}$ It is worthwhile to note that the composition gradients in the DADMs are about 100 times shallower than Miyazaki's gradients, making the "front effect" even less likely. A definitive test of this "front effect" would require making an alloy with its composition being the average composition of the small square boxes in Figure 3. After a very long-term homogenization and solutionizing heat treatment at $1200{ }^{\circ} \mathrm{C}$, the alloy would be quenched to ambient temperature and specimens cut from the alloy samples would be annealed at $900{ }^{\circ} \mathrm{C}$ for 5,50 , and 500 hours. If the $\chi$ phase sizes and distributions in these alloy specimens match those in the small square boxes in Figure 3, then "front effect" is minimal and can be ignored. If appreciable differences are observed in the $\chi$ phase sizes and distributions between the alloy specimens and those in the DADMs, then this "front effect" needs to be considered when extracting valuable information from high-throughput DADMs. In the latter case, phase-field simulations ${ }^{[4,45]}$ can be performed with and without the concentration gradients to evaluate the contribution of the "front effect" on the growth and coarsening of the $\chi$ precipitates.

Other hypotheses may emerge as more experimental information is gathered from DADMs and as more simulation results become available. For instance, interfacial diffusion might be considered if bulk diffusion growth and coarsening cannot explain all the observations. Various hypotheses should be tested in the future until a conclusive one is supported by all experimental and simulation results. Such an iterative and holistic study would be very valuable for future simulations of multicomponent alloys where sequential precipitation of one phase after another is quite common and the "abnormal" growth mechanism should be included in high-fidelity precipitation modeling for reliable property predictions.

\section{OPPORTUNITY TO COLLECT LARGE DATASETS ON PHASE TRANSFORMATIONS AND TO HOLISTICALLY COUPLE WITH MODELING TO ADVANCE MODEL CAPABILITIES}

More detailed high-resolution SEM characterizations together with selected TEM characterizations for phase identification can be performed to obtain high-resolution image atlases of various precipitates to evaluate their sizes and distributions at dozens of (e.g., 30) selected (but equivalent) locations (thus the same nominal compositions) on the DADMs that were annealed at $900{ }^{\circ} \mathrm{C}, 800{ }^{\circ} \mathrm{C}, 700{ }^{\circ} \mathrm{C}$ and $600{ }^{\circ} \mathrm{C}$ for different time durations. In other words, dozens of small square boxes similar to those in Figure 3 across the $\mathrm{Fe}-\mathrm{Cr}-\mathrm{Mo}$ region of the DADM samples can be examined using SEM to obtain image atlases to evaluate the precipitate size and distribution as a function of anneal temperature and time. The TC-PRISMA code $^{[42,43]}$ can be employed to simulate the precipitations of these dozens of "alloys" whose nominal compositions will be assumed to be those of the averages of each of the small square boxes/locations, respectively. It is anticipated that for most "alloys" whose compositions are away from the precipitation fronts and especially at shorter anneal times when a phase (metastable or stable) precipitates directly from the supersaturated $\alpha$ solid solution without the complication of sequential precipitations, TC-PRISMA might be able to simulate the precipitate size and distribution to a reasonable approximation. As a preliminary case study, a TC-PRISMA simulation was performed for an alloy of $\mathrm{Fe}-15 \mathrm{Cr}-6 \mathrm{Mo}$ (at. pct) which is equivalent to the composition of the green circles in Figure 3. The results are quite surprisingly close to the experimental measurements as shown in Figure 4. No adjustable parameters were used in this simulation since TC-PRISMA extracts the driving force directly from Thermo-Calc and the mobility data from DICTRA using coupled thermodynamic and kinetic databases. TC-PRISMA also directly estimates an interfacial energy value using an extended Becker's mode ${ }^{[46]}$ built into the code. In cases when the predicted precipitated sizes are different from the simulated values using the default interfacial energy values, one can adjust the interfacial energy values to simulate until the precipitate sizes and distributions match experimental observations at multiple temperatures and times for several locations (nominal compositions); in this way, one can obtain an effective interfacial energy for each kind of the precipitates. This is similar to the evaluation of interfacial energy between $\gamma^{\prime}$ and fcc phases in Ni-Al, Figure 2, but for ternary alloys and for several 
precipitate phases. Such interfacial energy values can then become essential input to more complicated simulations involving sequential phase precipitations.

The most recent releases of TC-PRISMA [since the $2017 \mathrm{~b}$ version] have implemented new capabilities to handle precipitates in the shapes of cuboids, needles, and plates. ${ }^{[4]}$ Once the program has additional input data of elastic properties of the precipitate and matrix phases as well as the transformation strains, it minimizes the sum of contributions from both the interfacial energy and the elastic strain energy, and outputs the time-dependent cuboid factor or the aspect ratio that describes the morphological evolution of non-spherical particles. Simulations of non-spherical shapes are a welcoming recent development ${ }^{[48-50]}$ that will expand the KWN modeling capabilities to a lot more engineering alloys such as Al alloys and Mg alloys with non-spherical precipitates. The new capabilities will also be very convenient for the simulation of non-spherical precipitates observed in the Fe-Cr-Mo compositions in the DADMs.

The systematic simulations over dozens of nominal compositions (e.g., 30 boxes/compositions) will serve both as an excellent test of the capabilities of the KWN models as implemented in TC-PRISMA and as a great opportunity to identify gaps to be filled or improved in the future. Such an holistic study will contribute significantly to the future capabilities in simulating complex precipitation processes often observed in engineering alloys and in applying them to design more advanced processing routes to achieve the optimum microstructures and properties.

Such holistic modeling effort would also be an integral part of understanding the "abnormal" $\chi$ precipitates as well as exploring ways to model sequential precipitations. Reliable interfacial energy values and other key parameters (for non-spherical precipitates) for the individual phases are the foundation for the simulation of sequential precipitations, which is needed to fully understand the "abnormal" phenomenon. Simulation of sequential precipitations is at the cutting-edge of modeling phase precipitations. The approaches employed by Perez and Deschamps ${ }^{[51]}$ and Du et al. ${ }^{[52]}$ can be adopted and expanded/built upon with the new understanding gained from studying the mechanism(s) of the "abnormal" size formation. The current TC-PRISMA code cannot handle sequential precipitations partly due to limited understanding of the processes. The time-series precipitate morphology atlases of the dozens of boxes/nominal compositions (many of which can be intentionally selected to contain sequential precipitations) will provide unprecedented opportunities to understand the sequential processes and test various approaches to simulate their microstructure evolutions as a function of time and temperature.

The above systematic study can be augmented by the combinatorial nature of DADMs, as illustrated with the help of Figure 6(a). The dashed box shows a systematic increase of $\chi$ precipitate size from right to left, following the progress of the "front" as anneal time increases at $900{ }^{\circ} \mathrm{C}$ [based on time-series data in Figure 3]. The $\mathrm{Cr}$ concentration is gradually changing from left to right
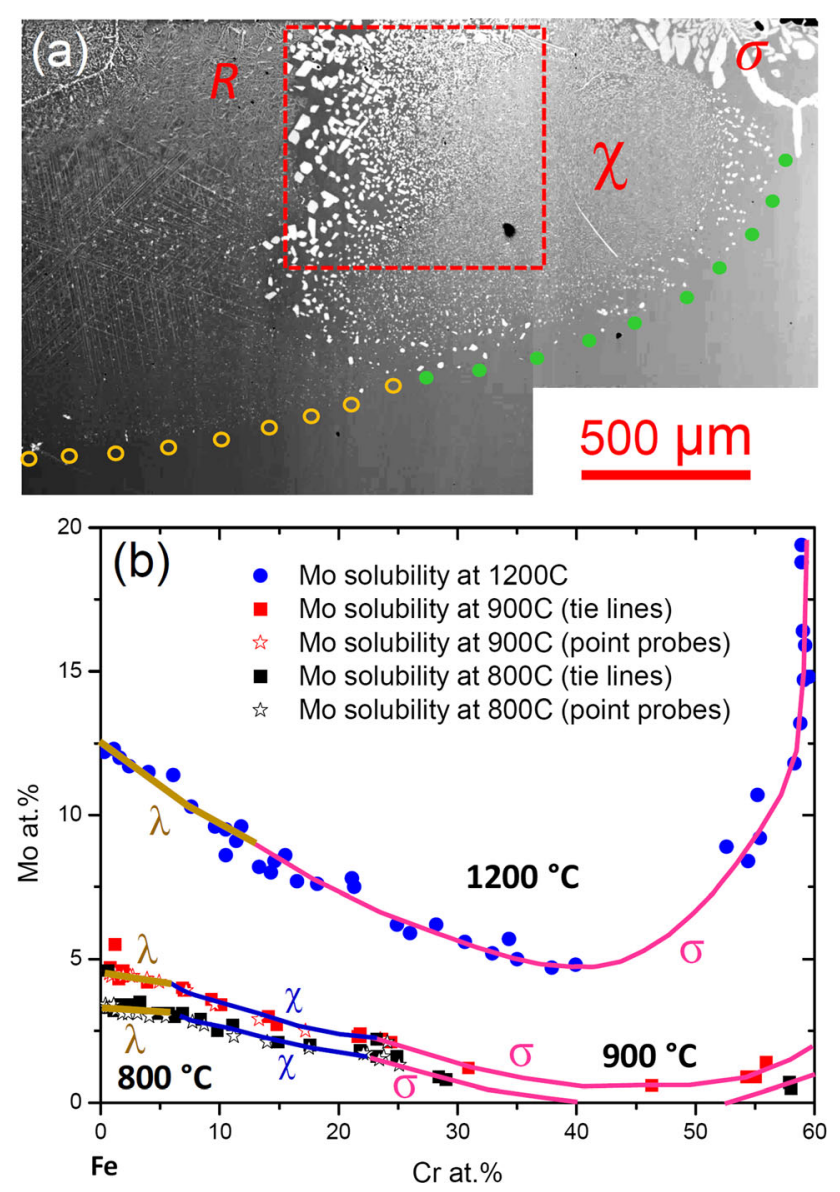

Fig. 6-(a) Part of Fig. 3(c) showing the precipitates with enhanced contrast and the point measurements for evaluation of solvi (see text for details); and (b) equilibrium solvi at $800{ }^{\circ} \mathrm{C}, 900{ }^{\circ} \mathrm{C}$, and $1200^{\circ} \mathrm{C}$ (from bottom to top) of the Fe-Cr-Mo system showing good agreement between point measurements and equilibrium tie-line data. The different color lines represent the specific phase in equilibrium with the $\alpha$ (bcc) phase. Figure modified and adapted from Ref. [3] with permission.

and so does the diffusion coefficients, which alone cannot to explain the size difference-TC-PRISMA simulations on $9 \mathrm{Cr}$ and $15 \mathrm{Cr}$ alloys show very little difference in the size of $\chi$ in the homogeneous nucleation, growth and coarsening cases. Moreover, from the top to the bottom of the same box, the Mo concentration is decreasing and so should the driving force for nucleation of the $\chi$ phase from the $\alpha$ matrix (may not be true for the nucleation of $\chi$ from the mixture of $\mathrm{R}$ and $\alpha$ - to be checked in the future), yet the $\chi$ size does not seem to change much from the top to the bottom of the box. Systematic simulations as described above aiming at explaining such trends will add understanding and/or confidence to the mechanism(s) gained from future studies as well as the approaches to be implemented to simulate sequential precipitations.

Some preliminary measurements of the average $\chi$ radius in the small vertical rectangular boxes in Figure 3 further illustrate the combinatorial nature of DADMs. The rate of growth and coarsening of the $\chi$ phase is faster than that in the green circles, as shown in Figure 4. There is no interference from the presence of 
other phases since even in the 5-hour anneal DADM, the precipitates are all $\chi$ already, Figure 3(a). It is all growth and coarsening from 5 to 50 to 500 hours. Why are the growth and coarsening of $\chi$ in the vertical rectangular boxes faster than the same $\chi$ in the green circles? One hypothesis is that the nucleation of $\chi$ phase from the mixture of the $\mathrm{R}$ and $\alpha$ phases (before 5 hours) has altered the $\chi$ phase size distribution which can lead to a different growth and coarsening rate. Such a difference was not observed or modeled before since in individual alloys, the LSW theory ${ }^{[38,39]}$ always assumes one particular size distribution. The altered size distributions by nucleating from the $\mathrm{R}$ and $\alpha$ mixture and/or from the "front effect" (even if true) created a "combinatorial" opportunity to decouple the growth and coarsening from the one particular size distribution as in the classical LSW or KWN models. Systematic simulations can be performed in the future to test various scenarios and hypotheses.

\section{OPPORTUNITY FOR SYSTEMATIC STUDIES OF METASTABILITY BY MAPPING SOLVI OF METASTABLE PHASES}

Accurate Gibbs free energy of metastable phases is very difficult to assess, but it is essential for computing the driving force for their precipitation. Density functional theory (DFT) calculations usually have an accuracy on the order of $\pm 1 \mathrm{~kJ} / \mathrm{mole}$, but accurate thermodynamic calculations require an accuracy of $\leq 0.1 \mathrm{~kJ} / \mathrm{mole}$. The best and most systematically assessed Gibbs energy values for metastable phases are for the Al-Cu binary system. ${ }^{[53]}$ This was accomplished through careful measurements ${ }^{[54-61]}$ of the solvi (solvuses) of the metastable phases via very careful precipitation studies on several alloys as a function of time and temperature, as summarized in Figure 7; and then employing the data to optimize the Gibbs energy functions using the CALPHAD approach. The computed solvi in Fig 7 show good agreement with experimental data (symbols in Figure 7) after fitting the Gibbs energy function parameters using the solvi. ${ }^{[62]}$ Such an assessment produces the most accurate Gibbs energy functions for the metastable phases, but is seldom performed for other binary systems, not to mention ternary systems, due to lack of the solvi data which are very time consuming to obtain for the metastable phases using individual alloys.

DADMs can be applied to efficiently obtain the solvus data for the metastable phases. The wide continuous variations of compositions created at the high-temperature $\left(1200{ }^{\circ} \mathrm{C}\right)$ anneal step of a DADM render ample opportunities to catch the solvus compositions at the second anneal temperature. DADMs catch the solvus by varying compositions at a constant (the precipitation anneal) temperature whereas the individual alloy studies catch the solvus by varying the temperature at each constant composition. This can be explained with the help of Figure 6(a) which is a contrast-enhanced image of the lower right part of Figure 3(c). EPMA composition analysis at the locations of the red dots which separate the single-phase $\alpha$ solid solution from the $\chi$

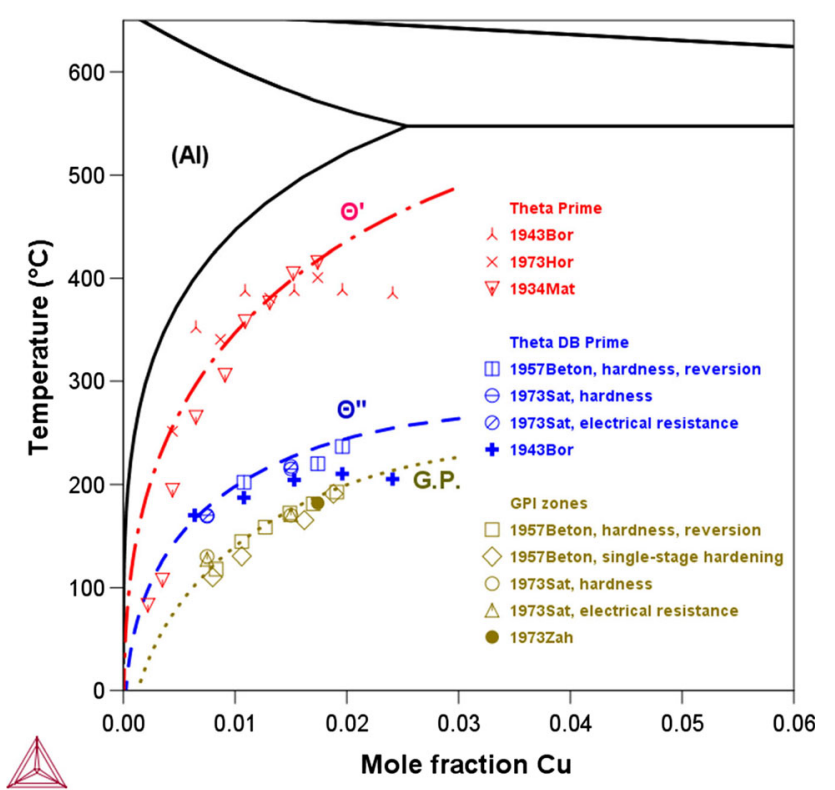

Fig. 7-Experimental (symbols) ${ }^{[53-61]}$ and fitted solvi ${ }^{[62]}$ of metastable phases in the Al-Cu system based on several sets of experimental measurements. ${ }^{[54-61]}$ Adapted from Ref [62] with permission.

precipitation region gives the solvus compositions for the $\chi$ phase. Since the $\chi$ phase is an equilibrium phase at $900{ }^{\circ} \mathrm{C}$, the solvus compositions are the same as the equilibrium $\alpha /(\alpha+\chi)$ phase boundary/solvus. The excellent agreement between direct EPMA point measurements along the precipitation front and the equilibrium phase boundaries evaluated independently from tie-lines validates this method for the solvus evaluation of the equilibrium phases as shown in Figure 6(b) (see also Figures 7, 12, and 16 in Reference 3). The same should be true for metastable phases; i.e., EMPA point measurements along the open circles at the lower left corner of Figure 6(a) should afford the solvus compositions of the corresponding metastable phase. Since DADMs have been annealed at four temperatures $\left(900{ }^{\circ} \mathrm{C}, 800\right.$ ${ }^{\circ} \mathrm{C}, 700{ }^{\circ} \mathrm{C}$, and $600{ }^{\circ} \mathrm{C}$ ), several such metastable solvi can be obtained as input to thermodynamic optimization of accurate Gibbs free energy functions of the metastable phases.

The Fe-Cr-Mo ternary system has five equilibrium intermetallic compounds: $\sigma, \mathrm{R}, \lambda, \mu$, and $\chi$. At least two additional metastable precipitate phases that do not belong to these five phases have been observed in the DADM experiments (their crystal structures are yet to be identified): the larger/brighter phase in the large square box in Figure 3(b) and the long-needle-shaped phase in Figures 3(c) and 6(a). Not all the solvi for all these phases at all four temperatures can be obtained since some of the metastable phases form at the expense of others, which complicated the interpretation of the "solvus" locations. The interplay of phase stability and precipitation kinetics is complex and caution will need to be exercised in a rigorous way as the exemplary $\mathrm{Al}-\mathrm{Cu}$ system was performed. ${ }^{[54-61]}$ The observation of different precipitate morphologies (thus likely different 
phases - not shown) at the precipitation fronts from the $\alpha$ phase matrix at the four temperatures suggests that several solvi can be obtained for the metastable phases of the Fe-Cr-Mo system. Such information would be hard to obtain using cast alloys.

For the purposes of illustration, the solvi of the known precipitates in the $\mathrm{Fe}-\mathrm{Cr}-\mathrm{Mo}$ ternary systems are computed using Thermo-Calc and the associated TCFE9 database, as shown in Figure 8. The experimentally measured solvi would be in the format of
Figures 8(c) and (d) but for four temperatures. Again, some of the solvi might not be able to be measured due to the complex interplay of sequential precipitation. The current computed solvi are not very accurate - one can see appreciable difference between the measured $900{ }^{\circ} \mathrm{C}$ solvi in Figure 6(b) and computed solvi in Figure 8(c) for the Fe-Cr-Mo system.

The far left part of the SEM images in Figure 3 is essentially a $\mathrm{Fe}-\mathrm{Mo}$ diffusion couple since $\mathrm{Cr}$ (at the far upper right corner) was too far away to diffuse into this

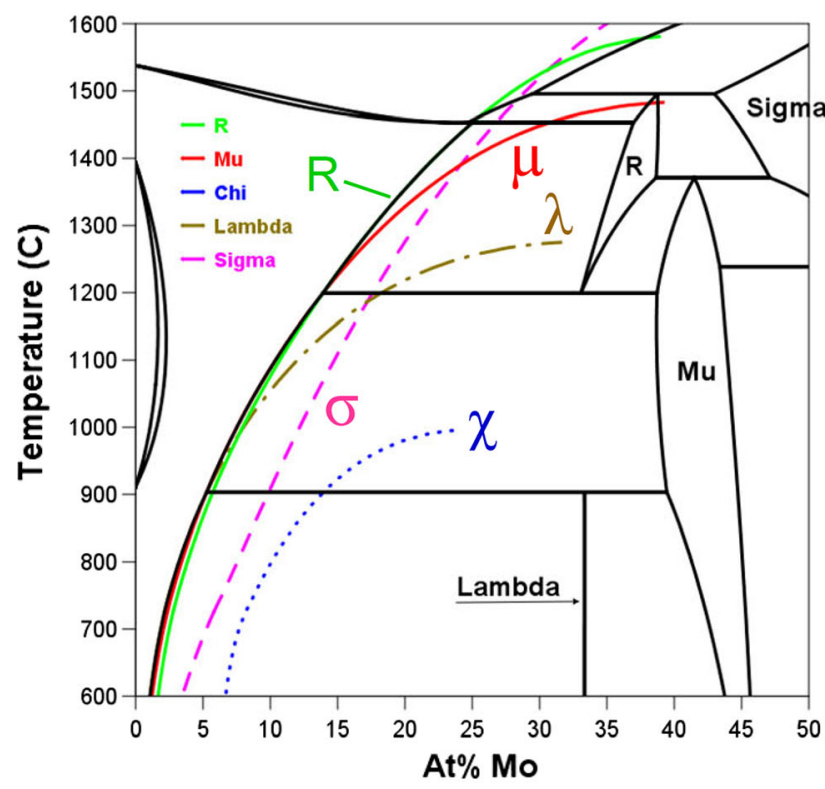

(a)

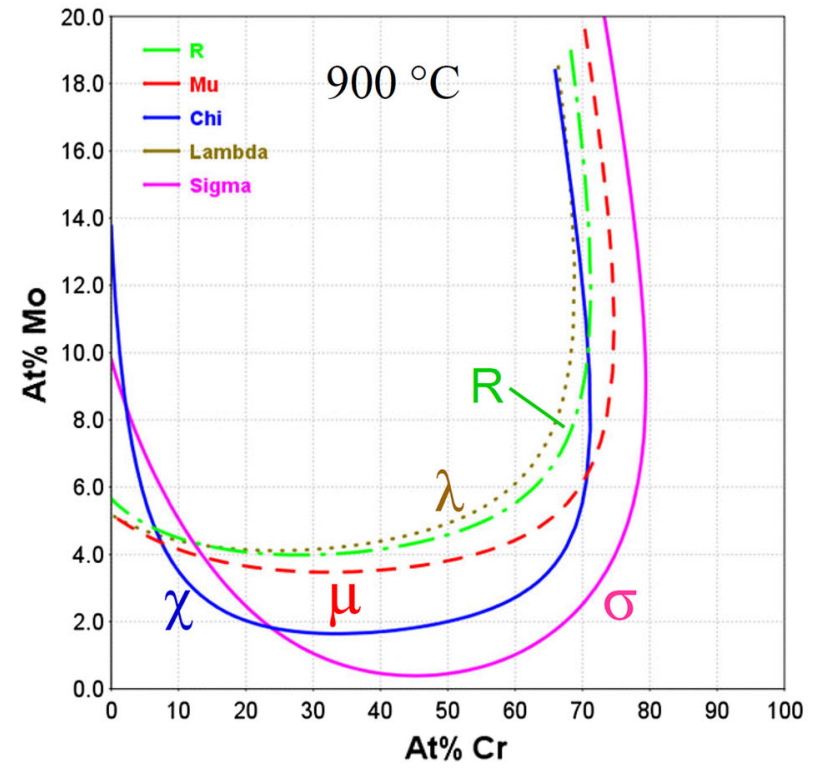

(c)

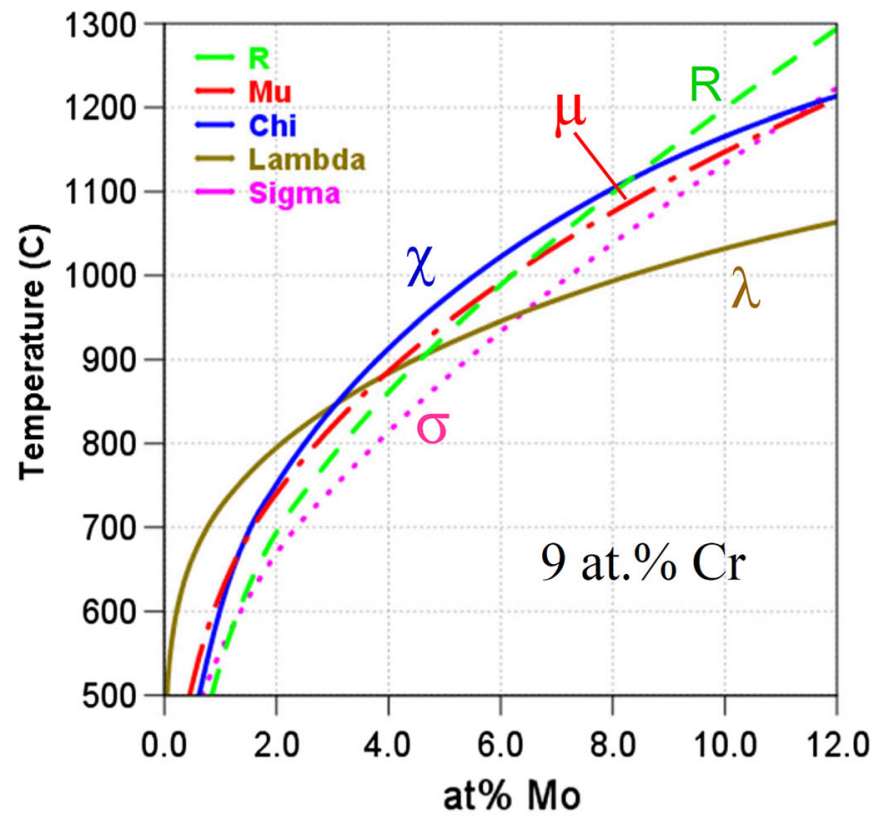

(b)

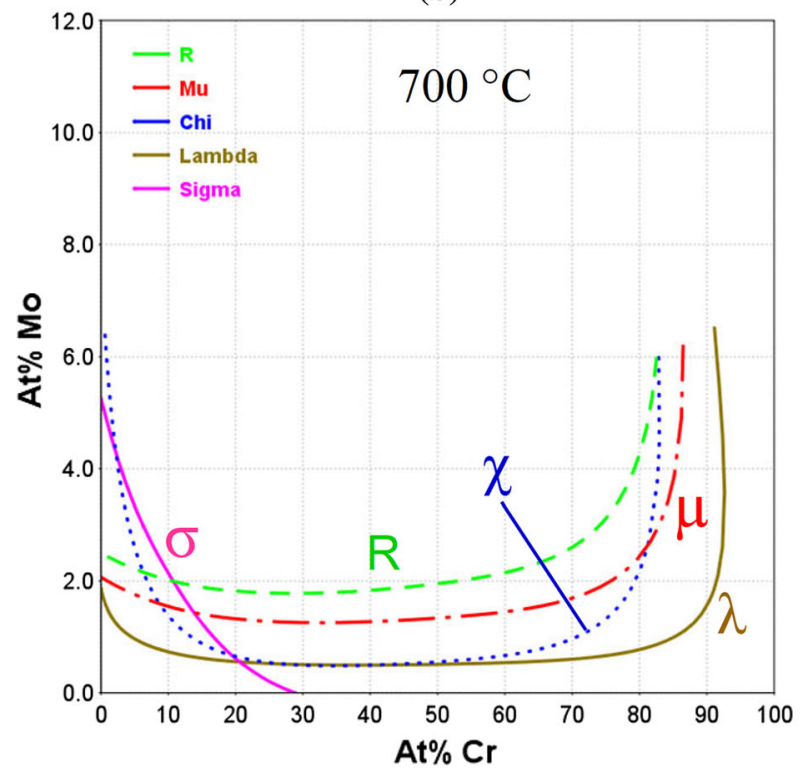

(d)

Fig. 8-Computed solvi for various metastable and stable phases in the Fe-Cr-Mo system using Thermo-Calc and the TCFE9 database: $(a)$ Solvi for the binary Fe-Mo system; (b) Solvi for an isopleth at 9 at. pct $\mathrm{Cr} ;(c)$ Solvi at $900{ }^{\circ} \mathrm{C}$ for various phases; and $(d)$ Solvi at $700{ }^{\circ} \mathrm{C}$ for various phases. 
part of the samples. Careful analysis of the solvi at four temperatures for this binary will help set the foundation for analyzing more complex ternary composition in the DADMs. The computed solvi for the Fe-Mo binary system is shown in Figure 8(a) for the purpose of illustration - they are not certain without the experimentally measured solvi data to help assess the Gibbs free energy of the metastable phases of this binary system.

In addition to the solvi, the direct observation of the phase precipitation sequences at the same location in DADMs also provides valuable information on the relative stability of the phases at the temperature of the second anneal. For instance, the fine precipitates inside the small square box in the middle of Figure 3(a) were identified as the R-phase by TEM characterization; however, the R-phase is only an equilibrium phase at high temperatures, not an equilibrium phase at $900{ }^{\circ} \mathrm{C}$. Thus, it can only appear as a metastable phase and with increasing anneal time, it should be consumed by the equilibrium phase (in this case by the equilibrium $\chi$ phase). One can also see that the fine R-phase precipitates inside the large square box in Figure 3(a) were consumed by another phase with larger precipitate size in the 50-hour annealed sample in Figure 3(b). This new phase has not been identified, but it is not a stable phase since after further anneal at $900{ }^{\circ} \mathrm{C}$ for 500 hours (Figure 3(c)), it was replaced by the long-needle-shaped phase which is again not an equilibrium one and yet to be identified. Only the final blocky phase that has formed at the expense of the long-needle phase was identified as the equilibrium $\lambda$ (Laves) phase. Thus, at the average/nominal composition of the large square boxes in Figure 3, stability sequence of the phases is: the $\lambda$ (Laves) phase $>$ the long-needle phase $>$ the brighter/ larger phase $>$ the R-phase. Such information is useful in evaluating the Gibbs energy of these phases.

It will be necessary to perform TEM crystal structure identification of the two yet-to-be-identified phases so that their heat of formation and other thermodynamic properties can be computed using DFT. The DFT data and the experimental observations in DADMs that have undergone heat treatments at different temperatures and for different durations will help place the phases in the right place in the complex free energy landscape of the Fe-Cr-Mo system. Accurate thermodynamic data are essential for understanding and modeling various phase transformations by providing accurate driving force values. The CALPHAD thermodynamic descriptions (parameters) for the Fe-Cr-Mo system need improvement since the computed isothermal sections based on existing thermodynamic data deviate significantly from recent experimental results at intermediate temperatures (see Figures 8 and 13 in Reference 3). The systematic mapping of the solvi of metastable phases will provide an opportunity to optimize more accurate Gibbs energy functions for the metastable phases of the Fe-Cr-Mo ternary system. Such a study will set an example of using high-throughput DADMs to effectively gather information on metastability to optimize accurate Gibbs energy for metastable phases.

\section{PHASE PRECIPITATION IN THE FE-CR-NI TERNARY SYSTEM}

The above results and discussion have been focused on the Fe-Cr-Mo system obtained from a set of Co-Cr-Fe-Mo-Ni DADMs showing in Figure 1(a). These DADMs also contain the Fe-Cr-Ni diffusion triple, as marked by a red square in Figure 1(a), and thus all the precipitation information, similar to the $\mathrm{Fe}-\mathrm{Cr}-\mathrm{Mo}$ system, is available for the same anneal conditions such as $1200{ }^{\circ} \mathrm{C}$ for 500 hours and subsequent precipitation anneal at $900{ }^{\circ} \mathrm{C}$ for 5,50 , and 500 hours, respectively. This section briefly summarizes the results obtained for the $\mathrm{Fe}-\mathrm{Cr}-\mathrm{Ni}$ ternary system. ${ }^{[2]}$

Figure 9 is an SEM image montage of the $\mathrm{Fe}-\mathrm{Cr}-\mathrm{Ni}$ tri-junction of the Co-Cr-Fe-Mo-Ni diffusion multiple that was annealed at $1200{ }^{\circ} \mathrm{C}$ for 500 hours and water quenched to ambient temperature (no second anneal yet), showing the $\gamma$ (fcc) phase on the top and the $\alpha$ (bcc) phase occupying most of the image area with a curved $\gamma /$ $\alpha$ interface running from the top left corner to the lower right corner of the montage. EPMA scans perpendicular to this interface at several locations provided the local equilibrium data that defined the tie lines as shown in Figure 1(c). It is clear that the $\mathrm{Fe}-\mathrm{Cr}-\mathrm{Ni}$ system has only two equilibrium phases, $\alpha$ and $\gamma$, at $1200{ }^{\circ} \mathrm{C}$. The solubility of $\mathrm{Ni}$ at $1200{ }^{\circ} \mathrm{C}$ is quite high ( 26 at. pct) in Cr-based $\alpha$ phase and it decreases with increasing $\mathrm{Fe}$ concentration in this phase. ${ }^{[2]}$

The $900{ }^{\circ} \mathrm{C}$ isothermal section of the Fe-Cr-Ni system in Figure 1(e) shows much reduced solubility of $\mathrm{Ni}$ in the $\alpha$ phase and the presence of the $\sigma$ phase as an equilibrium phase. The $1200{ }^{\circ} \mathrm{C}$ solubility line is superimposed on the $900{ }^{\circ} \mathrm{C}$ isothermal section in Figure 1(e) as the dashed red line to show the solubility difference. All the compositions in between this dashed red line and the $900{ }^{\circ} \mathrm{C}$ phase boundary (solubility line) of the $\alpha$ phase are supersaturated at $900{ }^{\circ} \mathrm{C}$ and the corresponding locations in DADMs will have $\gamma$ and $\sigma$ precipitates at different compositions after the being annealed at $900{ }^{\circ} \mathrm{C} .{ }^{[2]}$

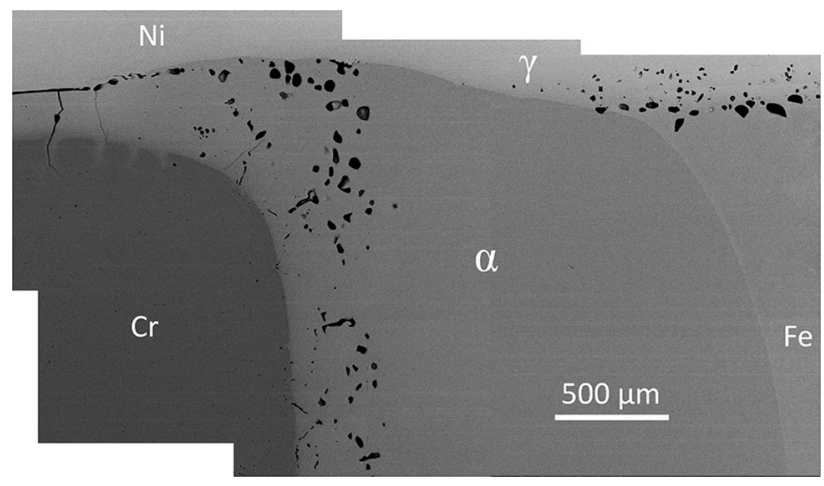

Fig. 9- SEM image montage of the $\mathrm{Fe}-\mathrm{Cr}-\mathrm{Ni}$ tri-junction of the Co-Cr-Fe-Mo-Ni diffusion multiple that was annealed at $1200{ }^{\circ} \mathrm{C}$ for $500 \mathrm{~h}$ and water quenched to ambient temperature showing $\alpha$ and $\gamma$ phases without precipitates in the vast $\alpha$ phase area. Reprinted with permission from Ref. [2]. 
Water quench after the $1200{ }^{\circ} \mathrm{C}$ anneal was able to retain all the single-phase composition to ambient temperature, showing no precipitates in the vast bcc phase region in the sample, even after careful examination using high-resolution SEM (The slight contrast changes in Figure 9 are not precipitates). The sharp contrast change near pure $\mathrm{Cr}$ is the result of sharp composition change due to very low diffusion coefficients and is not a phase interface.

Phase precipitations across the vast $\alpha$ phase region after being annealed at $900{ }^{\circ} \mathrm{C}$ for 5,50 and 500 hours, respectively, are showing in the SEM image montages in Figure 10. The contrast difference between the SEM images in each montage is artificial due to difficulty in matching both contrast and brightness while trying to show the precipitates. Except for the extremely large $\sigma$ phase precipitate in each montage, all the plate-like precipitates are the $\gamma$ phase and no metastable phases were observed, unlike the scenario in the $\mathrm{Fe}-\mathrm{Cr}-\mathrm{Mo}$ systems. The $\gamma$ phase precipitates developed well-organized Widmanstätten pattern, especially in the DADMs that were annealed for 50 and 500 hours.

One can put dozens of small circles or squares at the same equivalent locations cross the montages and collect time-dependent precipitate morphology and size for dozens of compositions. The dataset would be equivalent to studying the precipitation behavior of dozens of individual alloys, but at a much higher efficiency.

Preliminary TC-PRISMA simulations were performed to predict the $\gamma$ phase size using representative compositions and compared with the experimental results in Figure 10. Various non-spherical models were attempted, but the simulated $\gamma$ phase sizes are substantially smaller than the experimentally observed Widmanstätten $\gamma$ precipitates showing in Figure 10. The difference calls for more systematic simulation investigations to understand the mechanistic difference and for incorporation of the understanding into KWN type of simulation programs such as TC-PRISMA to enable accurate predictions.

\section{OPPORTUNITY FOR SYSTEMATIC STUDIES OF MASSIVE TRANSFORMATIONS}

Massive transformation is dictated by interface motion, thus it is much faster than precipitations whose kinetics are dictated by long-range diffusion. The $\alpha$ to $\sigma$ massive transformation in the $\mathrm{Fe}-\mathrm{Cr}-\mathrm{Ni}$ system is very evident by the enormous size of the $\sigma$ phase in comparison with the $\gamma$ phase precipitates in Figure 10. The size of the $\sigma$ phase is more than $500 \mu \mathrm{m}$ in one dimension (horizontal) and $\sim 1000 \mu \mathrm{m}$ in the other (vertical) even after only 5 hours of anneal at $900{ }^{\circ} \mathrm{C}$, which is orders of magnitude larger than the $\gamma$ phase precipitates formed under the same conditions, Figure 10(a). The $\sigma$ phase only grew slightly from 5 to 50 to 500 hours, as shown in Figure 10. It is noted that the $\sigma$ phase is a much more complicated crystal structure than the fcc $\gamma$ phase, thus its kinetics would presumably be much slower than that of the $\gamma$ phase if both were to

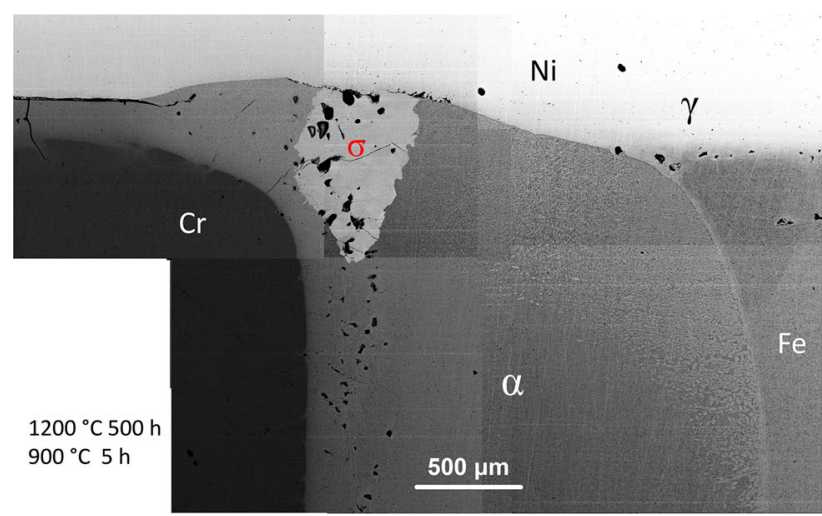

(a)

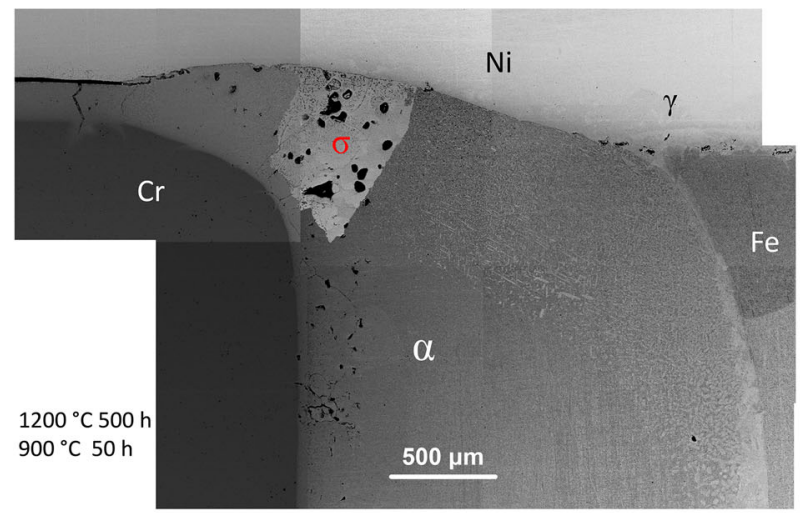

(b)

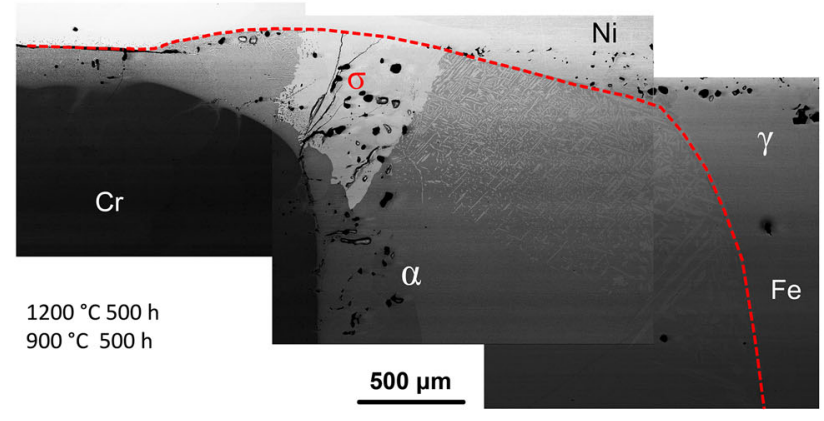

(c)

Fig. 10-SEM image montages showing the phase precipitation in the $\mathrm{Fe}-\mathrm{Cr}-\mathrm{Ni}$ tri-junction area of DADMs that were annealed at $1200{ }^{\circ} \mathrm{C}$ for $500 \mathrm{~h}$ to form wide range of solid solution compositions and then annealed at $900{ }^{\circ} \mathrm{C}$ for different durations to show the precipitation morphology and distribution as a function of anneal time at $900{ }^{\circ} \mathrm{C}$ from $5 \mathrm{~h}(a)$ to $50 \mathrm{~h}(b)$ to $500 \mathrm{~h}(c)$. (c) is reprinted with permission from Ref. [2].

form through the same precipitation (long-range) mechanism.

It is noted that study of massive transformations using DADMs follows what Borgenstam and Hillert ${ }^{[20]}$ did two decades ago except for the fact that DADMs extend the methodology to ternary systems.

Two analyses helped to confirm the $\alpha$ to $\sigma$ massive transformation: (1) there is no composition change across the interface between the large $\sigma$ phase and the surrounding $\alpha$ matrix; and (2) thermodynamic calculations show that the molar Gibbs free energy of the $\sigma$ 
phase is lower than that of the parent $\alpha$ phase in the compositions that have transformed from $\alpha$ to $\sigma$, thus satisfying the thermodynamic condition for direct transformation from $\alpha$ to $\sigma$ without any composition change. ${ }^{[2]}$

With the information observed in Figure 10, one can perform a detailed mechanistic study of the $\alpha$ to $\sigma$ massive transformation by using focused ion beam (FIB) to cut a thin foil from the location of the $\sigma$ phase but from the $1200{ }^{\circ} \mathrm{C}$-annealed and quenched sample (Figure 9). The foil should consist of only the $\alpha$ phase. In-situ transmission electron microscopy (TEM) studies can be performed using a hot stage to record the $\alpha$ to $\sigma$ transformation nucleation and growth kinetics. Detailed interface transformation mechanism can also be studies, especially using a state-of-the-art aberration corrected microscope with atomic scale resolution. Such mechanistic knowledge is still lacking. One advantage of the Fe-Cr-Ni system for an in-situ TEM study is that the kinetics is very fast, less than 5 hours, thus one does not need to wait for many hours on a microscope waiting for the transformation to take place.

The same type of $\alpha$ to $\sigma$ massive transformation took place in the Fe-Cr-Mo ternary system, as shown in Figure 3. The $\sigma$ phase can be seen at the upper right corner of the montages and has a size larger than $500 \mu \mathrm{m}$. The large size of the $\sigma$ phase is less apparent in Figure 3 due to the fact that cracks formed in the $\sigma$ phase and its surrounding area during quench from $900{ }^{\circ} \mathrm{C}$ after the respective anneal (5, 50 or 500 hours), making the large size of the $\sigma$ phase look fragmented. A similar TEM study as described above can be performed on FIB samples extracted from the Fe-Cr-Mo region to be compared with the results from the $\mathrm{Fe}-\mathrm{Cr}-\mathrm{Ni}$ region to see how the slow moving Mo in comparison with $\mathrm{Ni}$ affects the massive transformation kinetics and mechanism.

It is worthwhile to note that diffusion multiples have been employed to effectively study diffusionless martensitic transformations. ${ }^{[63]}$ Two sets of diffusion multiples were able to reveal the different effects of nine elements (Pt, Ta, Cr, Mo, Re, W, Zr, Si, and Co) on the martensitic transformation in the $\beta$-NiAl phase. ${ }^{[63]}$

\section{IDENTIFICATION OF PRECIPITATE PHASES FOR STRENGTHENING ALLOYS}

In addition to being an efficient and systematic way of studying phase transformations, DADMs can be employed to effectively identify strengthening phases for alloys, especially alloys for high-temperature applications when coarsening becomes a detrimental effect on long-term creep strength. Under this consideration, the $\gamma$ phase would not be a good strengthening phase for bcc-based (ferritic) steels since it grows too fast and to very large sizes at $900{ }^{\circ} \mathrm{C}$ even after only 500 hours, Figure 10. Such a high growth and coarsening rate would render the initially fine and effective strengthening precipitates much less effective, and thus degrades the mechanical properties substantially over time. Such a steel would not be capable of being used at $900{ }^{\circ} \mathrm{C}$ for years. The $\sigma$ phase is not a viable strengthening phase for high-temperature ferritic steels either, since it can form via the extremely fast massive transformation and would grow to large sizes thus not effective for strengthening.

In comparison, the $\chi$ phase and the Laves phase in the $\mathrm{Fe}-\mathrm{Cr}-\mathrm{Mo}$ system are more attractive as strengthening phases since they retain fine sizes and uniform distribution in the DADM that was annealed at $900{ }^{\circ} \mathrm{C}$ for 500 hours, Figure 3(c). The $\chi$ phase precipitates in the $\alpha$ matrix are very homogenous and equiaxed as shown in Figure 3, thus may be a worthwhile candidate to be explored as a strengthening phase for Fe-Cr-Mo-based ferritic steels even though the coarsening kinetics is still higher than desirable.

Even though the size of the R-phase in the Fe-Cr-Mo system remains fine in the DADM that was annealed at $900{ }^{\circ} \mathrm{C}$ for 500 hours, Figure 3(c), this phase is not a good choice as a strengthening phase for the $\mathrm{Fe}-\mathrm{Cr}-$ Mo-based ferritic steels since it is metastable at $900{ }^{\circ} \mathrm{C}$ and below. Over long periods of time, the R-phase would be transforming to more stable phase(s) to lose the strengthening effect. Such long-term stability information is already available by examining the information of DADMs to avoid wasting time on alloy development based on the R-phase strengthening.

A Fe-Cr-Mo-based ferritic steel strengthened by the $\chi$ phase precipitates was explored and found to have a creep strength comparable to the $9 \mathrm{Cr}$ steels which have been in development over many year. ${ }^{[64]}$ If additional minor elements can be added to reduce the growth rate of the $\chi$ phase, alloys strengthened with the $\chi$ phase may have a future as successful ferritic stainless steels. To speed up the experimental identification of heat treatment conditions for optimal strength, a gradient-temperature heat treatment process was developed using a simple tube furnace with one end open and the other end closed. The natural temperature gradient at the open end of a tube furnace enabled a $400{ }^{\circ} \mathrm{C}$ temperature gradient to be leveraged for the high-throughput experiment. $^{[64]}$

\section{SUMMARY REMARKS}

The Co-Cr-Fe-Mo-Ni diffusion multiple set (Figure 1) contained 8 ternary systems and the high-temperature annealed diffusion multiples were cut into several slices and annealed at 4 temperatures (900 to $600{ }^{\circ} \mathrm{C}$ ) for various anneal durations. Such multiplication effect $(8 \times 4 \times$ number of alloys $\times$ number of anneal durations) greatly accelerates the data gathering in comparison with the traditional individual alloy approach which would require dozens of individually made alloys for each ternary system. One can appreciate the enormous efficiency gain provided by DADMs in studying phase transformations.

It is a bit overwhelming to go through the preliminary data obtained from just two ternary systems (Fe-Cr-Mo and $\mathrm{Fe}-\mathrm{Cr}-\mathrm{Ni})$ at one anneal temperature $\left(900{ }^{\circ} \mathrm{C}\right)$ as described in this article, one can imagine the amount of detailed data that can be collected from all 8 ternary systems at multiple temperatures and anneal durations. 
For each ternary system inside each individual DADM, high-resolution SEM images can be taken from dozens of square box locations (compositions) in DADMs that were annealed at four temperatures for different durations $(5,50$, and 500 hours) to build dozens of atlases of precipitate microstructures (phase, size, shape, and distribution) as a function of temperature and time. Simulations using state-of-the-art KWN models as implemented in the TC-PRISMA code can be iteratively performed to match the time- and temperature-dependent precipitate size and distribution to effectively obtain key parameters such as interfacial energy and shape related parameters for non-spherical precipitates for boxes/compositions where only one phase precipitated from the $\alpha$ matrix. Various mechanistic hypotheses of nucleation and growth (and coarsening) of new phases from metastable precipitates can be iteratively tested using KWN simulations or other models such as phase field to match the microstructure evolution in many of locations (among the dozens) where sequential precipitations took place. After testing various hypotheses, some mechanism(s) might be able to explain the "abnormal" $\chi$ precipitates as well as the "combinatorial" gradient morphologies observed in the dashed box in Figure 6(a). The validated working mechanism(s) can then be implemented into future simulation packages to enable more robust simulations of sequential precipitations of phases including non-spherical precipitates. Such an approach iteratively and holistically integrate vast experimental data with model predictions shall be highly effective.

Metastable phases and their transitions to more stable phases have been systematically observed in the $\mathrm{Fe}-\mathrm{Cr}-\mathrm{Mo}$ ternary system across a wide range of composition, temperature, and anneal time, thus providing large amount of information on metastability of the phases. The solvi of the metastable and stable phases can be systematically collected for more reliable CALPHAD assessments of the Gibbs free energy of the metastable phases which further lead to accurate calculations of the driving force for precipitation.

DADMs will be an excellent test case for a digital microstructure information ecosystem that handles data collection, analysis, and management. In the Fe-Cr-Mo tri-junction alone, the precipitates range from nanometers to millimeters in size, from spheres to plates to needles in shape, and from very homogenous to very heterogeneous in distribution. There will be significant challenges to data collection and fusion such as how to effectively stitching images together with nanometer scale and millimeter scale features and correlating them to the overall compositions of the locations.

It is also worth noting that after the first anneal at $1200{ }^{\circ} \mathrm{C}$ for 500 hours, the grain size of the solid solution phases in the diffusion multiples grew very large. One can see only a few grain boundaries in the entire view areas in Figures 3 and 10; thus, the phase transformation results obtained from local areas inside the DADMs are equivalent to high-quality data from single crystals.

DADMs can be employed to effectively study massive transformations as explained in Section VIII and to identify precipitate phases that can be used to design new alloys as described in Section IX.

DADMs not only enable much higher efficiency in collecting datasets for studying phase transformations, their wide ranges of continuously varying compositions created by the high-temperature interdiffusion process but also provide unique opportunities to catch phenomena that otherwise would be missed during studies using individual alloys. The "abnormal" sizes of the $\chi$ phase as it consumed the metastable phases at its left reaction front in Figures 3 and 4 is one of such unusual observations that have escaped all previous phase transformation studies using individual alloys of specific compositions. The systematic nature of the DADM experiments may lead to new findings.

\section{ACKNOWLEDGMENTS}

A majority of this study was funded by the National Science Foundation (NSF) under Awards \#1237577 and \#1904245, both from the NSF Division of Materials Research (DMR). This study also benefited from the results of NSF Award $\# 1825560$ (re-issued to University of Maryland as \#2004979) from NSF Division of Civil, Mechanical, and Manufacturing Innovation (CMMI). The author is grateful for his students, especially Drs. Siwei Cao and Changdong Wei, for taking some of the images presented in this review. Some hypotheses and analyses presented in this article are preliminary, meant to stimulate discussions, out of the box thinking, and future work to leverage the very effective DADM methodology. The author is also grateful to Dr. Qing Chen for valuable discussions related to the solvus calculations for metastable phases and to Drs. Qiaofu Zhang, Surendra Makineni, and John Allison for contributing to the interfacial energy evaluation in the $\mathrm{Ni}-\mathrm{Al}$ system which is used as an example to introduce the DADM concept via Figure 2.

\section{REFERENCES}

1. J.-C. Zhao: Adv. Eng. Mater., 2001, vol. 3, pp. 143-47.

2. S. Cao and J.-C. Zhao: Acta Mater., 2015, vol. 88, pp. 196-206.

3. S. Cao and J.-C. Zhao: J. Phase Equilib. Diffus., 2016, vol. 37, pp. $25-38$.

4. L. Zhu, C. Wei, H. Qi, L. Jiang, Z. Jin, and J.-C. Zhao: J. Alloys Compds., 2017, vol. 691, pp. 110-18.

5. L. Zhu, C. Wei, L. Jiang, Z. Jin, and J.-C. Zhao: Intermetallics, 2018, vol. 93, pp. 20-29.

6. Q. Zhang and J.-C. Zhao: Intermetallics, 2013, vol. 34, pp. 132-41.

7. Q. Zhang and J.-C. Zhao: J. Alloys Compd., 2014, vol. 604, pp. $142-50$.

8. Q. Zhang, Z. Chen, W. Zhong, and J.-C. Zhao: Scr. Mater., 2017, vol. 128 , pp. $32-35$.

9. L. Zhu, Q. Zhang, Z. Chen, C. Wei, G. Cai, L. Jiang, Z. Jin, and J.-C. Zhao: J. Mater. Sci., 2017, vol. 52, pp. 3255-68.

10. Z. Chen, Z.-K. Liu, and J.-C. Zhao: Metall. Mater. Trans. A, 2018, vol. 49A, pp. $3108-16$.

11. J.-C. Zhao: Prog. Mater. Sci., 2006, vol. 51, pp. 557-631.

12. S. Huxtable, D.G. Cahill, V. Fauconnier, J.O. White, and J.-C. Zhao: Nature Mater., 2004, vol. 3, pp. 298-301. 
13. J.-C. Zhao, X. Zheng, and D.G. Cahill: Scr. Mater., 2012, vol. 66, pp. $935-38$.

14. C. Wei, X. Zheng, D.G. Cahill, and J.-C. Zhao: Rev. Sci. Instr., 2013, vol. 84, p. 071301.

15. X. Zheng, D.G. Cahill, R. Weaver, and J.-C. Zhao: J. Appl. Phys., 2008, vol. 104, p. 073509

16. X. Du, J.-C. Zhao, and N.P.J. Comput: Mater., 2017, vol. 3, pp. 17-1-17-8.

17. X. Du and J.-C. Zhao: Scripta Mater., 2018, vol. 152, pp. 24-26.

18. W.C. Oliver and G.M. Pharr: J. Mater. Res., 1992, vol. 7, pp. 1564-83.

19. W.C. Oliver and G.M. Pharr: J. Mater. Res., 2004, vol. 19, pp. 3-20.

20. A. Borgenstam and M. Hillert: Acta Mater., 2000, vol. 48, pp. 2765-75.

21. A. Borgenstam and J.M. Ericsson, in Proceedings of the International Conference on Solid-Solid Phase Transformations in Inorganic Materials 2005, Edited by J.M. Howe, D.E. Laughlin, J.K. Lee, U. Dahmen and W.A. Soffa, Wiley-TMS, 2005, pp. 105-10.

22. A. Phillion, H.W. Zurob, C.R. Hutchinson, H. Guo, D.V. Malakhov, J. Nakano, and G.R. Purdy: Metall. Mater. Trans. A, 2004, vol. 35, pp. 1237-42.

23. C.R. Hutchinson, A. Fuchsmann, H.S. Zurob, and Y. Bréchet: Scr. Mater., 2004, vol. 50, pp. 285-90.

24. C.W. Sinclair, C.R. Hutchinson, and Y. Bréchet: Metall. Mater. Trans. A, 2007, vol. 38, pp. 821-30.

25. S. Hata, K. Shiraishi, M. Itakura, N. Kuwano, T. Nakano, and Y. Umakoshi: Philos. Mag. Lett., 2005, vol. 85, pp. 175-85.

26. E. Contreras-Piedras, H.J. Dorantes-Rosales, V.M. López-Hirata, F. Hernández Santiago, J.L. González-Velázquez, and F.I. López-Monrroy: Mater. Sci. Eng. A, 2012, vol. 558, pp. $366-70$.

27. T. Miyazaki: Prog. Mater. Sci., 2012, vol. 57, pp. 1010-60.

28. R.K.W. Marceau, C. Qiu, S.P. Ringer, and C.R. Hutchinson: Mater. Sci. Eng. A, 2012, vol. 546, pp. 153-61.

29. F. De Geuser, M.J. Styles, C.R. Hutchinson, and A. Deschamps: Acta Mater., 2015, vol. 101, pp. 1-9.

30. E. Gumbmann, F. De Geuser, A. Deschamps, W. Lefebvre, F. Robaut, and C. Sigli: Scr. Mater., 2016, vol. 110, pp. 44- 47.

31. R. Ivanov, A. Deschamps, and F. De Geuser: Scr. Mater., 2018, vol. 150 , pp. $156-59$.

32. Q. Zhang, S.K. Makineni, J. Allison, and J.-C. Zhao: Scr. Mater., 2019, vol. 160 , pp. 70-74.

33. R. Kampmann and R. Wagner, in Decomposition of Alloys: The Early Stages, Pergamon, Oxford, 1984, pp. 91-103.

34. R. Wagner, R. Kampmann and P. W. Voorhees, in Phase Transformations in Materials, Edited by Gernot Kostorz, Weinheim: Wiley, 2001, pp. 309-407.

35. A. Borgenstam, L. Höglund, J. Ågren, and A. Engström: J. Phase Equilib., 2000, vol. 21, pp. 269-80.

36. B. Sundman, B. Jansson, and J.-O. Andersson: CALPHAD, 1985, vol. 9, pp. 153-90.

37. J.-O. Andersson, T. Helander, L. Höglund, P. Shi, and B. Sundman: CALPHAD, 2002, vol. 26, pp. 273-312.
38. C. Zener: J. Appl. Phys, 1949, vol. 20, pp. 950-53.

39. I. Lifshitz and V. Slyozov: J. Phys. Chem. Solids, 1961, vol. 19, pp. $35-50$.

40. C. Wagner: Z. Elektrochem., 1961, vol. 65, pp. 581-91.

41. M. Perez, M. Dumont, and D. Acevedo-Reyes: Acta Mater., 2008, vol. 56, pp. 2119-32.

42. Q. Chen, J. Jeppsson, and J. Ågren: Acta Mater., 2008, vol. 56, pp. $1890-96$.

43. Q. Chen, K. Wu, G. Sterner, and P. Mason: J. Mater. Eng. Perf., 2014, vol. 23, pp. 4193-96.

44. L.-Q. Chen: Annu. Rev. Mater. Sci., 2002, vol. 32, pp. 113-40.

45. J.P. Simmons, C. Shen, and Y. Wang: Scripta Mater., 2000, vol. 43, pp. 935-42.

46. R. Becker: Ann. Phys., 1938, vol. 424, pp. 128-40.

47. K. Wu, Q. Chen, and P. Mason: J. Phase Equili. Diffu., 2018, vol. 39, pp. 571-83.

48. D. Bardel, M. Perez, D. Nelias, A. Deschamps, C.R. Hutchinson, D. Maisonnette, T. Chaise, J. Garnier, and F. Bourlier: Acta Mater., 2014, vol. 62, pp. 129-40.

49. B. Holmedal, E. Osmundsen, and Q. Du: Metall. Mater. Trans. A., 2016, vol. 47A, pp. 581-88.

50. Q. Du, B. Holmedal, J. Friis, and C.D. Marioara: Metall. Mater. Trans. A., 2016, vol. 47, pp. 589-99.

51. M. Perez and A. Deschamps: Mater. Sci. Eng. A., 2003, vol. 360, pp. 214-19.

52. Q. Du, K. Tang, C.D. Marioara, S.J. Andersen, B. Holmedal, and R. Holmestad: Acta Mater., 2017, vol. 122, pp. 178-86.

53. J. Murray, 'Al-Cu (Aluminum-Copper)', Phase Diagrams of Binary Copper Alloys, P.R. Subramanian, D.J. Chakrabarti, and D. E. Laughlin, Ed., ASM International, Materials Park, Ohio, 1994, pp. 18-42.

54. K. Matsuyama: Kinzoku no Kenkyu, 1934, vol. 11, pp. 461-90.

55. G. Borelius, J. Anderson, and K. Gullberg: Ing. Vetenskaps Akad. Handl., 1943, vol. 169, pp. 5-37.

56. R. H. Beton, Beton, and E.C. Rollason, J. Inst. Met., 1957-1958, vol. 86 , pp. 77-84.

57. R. Baur and V. Gerold: Z. Metall., 1966, vol. 57, pp. 181-86.

58. R. Baur: Z. Metall., 1966, vol. 57, pp. 275-80.

59. H. Hori and K. Hirano: J. Jpn. Inst. Met., 1973, vol. 37, pp. $142-48$.

60. K.G. Satyanarayana, K. Jayapalan, and T.R. Ananthraman: Current Sci., 1973, vol. 41 (1), pp. 6-9.

61. A.M. Zahra, M. Laffitte, P. Vigier, and M. Wintenberger: C.R. Acad. Sci., 1973, vol. 277, pp. 923-25.

62. H.-L. Chen, Q. Chen, J. Bratberg, and A. Engström: Mater. Today Proc., 2015, vol. 2, pp. 4939-48.

63. R.J. Thompson, J.-C. Zhao, and K.J. Hemker: Intermetallics, 2010, vol. 18 , pp. $796-802$

64. C. Wei and J.-C. Zhao: Materialia, 2018, vol. 3, pp. 31-40.

Publisher's Note Springer Nature remains neutral with regard to jurisdictional claims in published maps and institutional affiliations. 